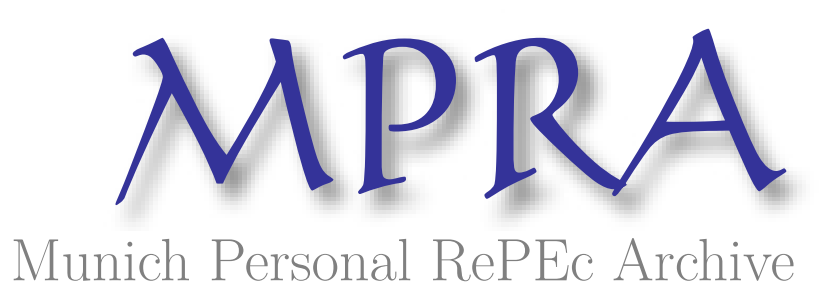

\title{
Shipping the good apples under strategic competition
}

\author{
Creane, Anthony \\ University of Kentucky
}

May 2019

Online at https://mpra.ub.uni-muenchen.de/93744/

MPRA Paper No. 93744, posted 10 May 2019 02:04 UTC 


\title{
Shipping the good apples under strategic competition*
}

\author{
Anthony Creane ${ }^{\dagger}$
}

May 8, 2019

\begin{abstract}
Production runs suffer from inadvertent quality variation. There are good apples; there are bad apples (also known as "seconds"). The Alchian-Allen theorem states that a common perunit charge on two goods differentiated only by quality, increases the relative export demand for the higher quality good leading to local consumers lamenting that they cannot find them locally. While usually stated for competitive markets, firms with market power also suffer from inadvertent seconds in their production. For example, brand-name retailers send their seconds to outlets, even though this undercuts the demand for their firsts. A model is presented of oligopolistic firms choosing production and what fraction of their first and seconds to export: a model of "shipping the good apples" with strategic competition. In this model an increase in the per-unit charge can increase the absolute fraction of high quality exported. Despite this, shipping the good apples may not hold, that is, an increase in the per-unit charge can decrease the quantity demanded of good apples relative to bad ones. Rather, shipping the good apples holds when the export market's willingness-to-pay for high quality is greater (or greater value for "quality upgrading" (Johnson and Myatt, 2006)). Despite the consumers' lament, domestic consumer welfare increases with exporting.

Keywords: Market power, Cournot, quality, trade.

JEL classification: D3, F12
\end{abstract}

*I thank Jose Asturias, Dmitry Lubensky, Zijun Luo, Phillip McCalman, Santanu Roy, and Ed Schlee, as well as participants at the 2017 IIOC and in particular Zijun Luo, 2017 Midwest Economic Theory Conference at SMU, 2018 Midwest International Trade Conference at Drexel, EARIE 2018 Athens, XXXIII Jornadas de Economia Industrial Barcelona, Lisbon Meetings in Game Theory and Applications, American University Beirut, and University of Kentucky seminar for their valuable comments. This paper was revised while I was a visiting scholar at Department of Economics and Business, Universitat Pompeu Fabra, and I am grateful for their support.

${ }^{\dagger}$ Department of Economics, University of Kentucky, Lexington, KY 40506; USA a.creane@uky.edu. Visiting Scholar, Department of Economics and Business, Universitat Pompeu Fabra 2018/9 


\section{Introduction}

The Alchian and Allen (1964) theorem ${ }^{1}$ is commonly known as the "shipping the good apples" theorem as a result of a Seattle Times article Borcherding and Silberberg (1978) cite in which a consumer laments the lack of good, locally produced apples:

Why are Washington apples in local markets so small and old-looking? The driedup stems might seem they were taken out of cold storage from some gathered last year....Where do these big Delicious apples go? Are they shipped to Europe, to the East or can they be bought here in Seattle?

This effect of the best apples being exported while the "seconds" stay at home resonates with many because they themselves have observed it. This casual empiricism has been confirmed with recorded instances including examples cited in Creane and Jeitschko (2015): roses in Tanzania, coffee in Indonesia, and tea in India. This theoretical result has gathered recent empirical interest following Hummels and Skiba (2004) empirical testing of the phenomenon in international trade and the subsequent empirical papers.

Although the Alchian-Allen effect is rooted in the competitive market with perfectly elastic supply, the phenomenon of bad apples (fixed fraction of 'seconds' from production) and disproportionately exporting the good apples can occur in non-perfectly competitive markets. Indeed, the sorting of product into higher and lower quality has an established history with branded products. For example, Bordeaux wineries (and others like Opus One) have "first" and "second" wine, where the latter are the grapes deemed of inferior quality, with the amount appearing as firsts varying from year to year (Wikipedia, 2019). Even seemingly competitive markets like coffee and roses often have their export coordinated by a cooperative with market power (e.g., National Federation of Coffee Growers of Colombia "Juan Valdez" Norton and Dann 2013) or vertically integrated into the destination market. The sorting of quality does not only occur with agricultural products, as in manufacturing output is often sorted by quality with "factory seconds," "minor imperfections," and "factory

\footnotetext{
${ }^{1}$ Borcherding and Silberberg (1978) state it as "a common charge on two substitute goods leads, real income held constant, to a relative increase in the consumption of the higher to lower quality commodity."
} 
refurbished" (e.g., on Amazon), which compete with firsts. ${ }^{2}$ These lower quality "seconds" can be traded, as, for example, on Sierra Trading Post, many of the "seconds" are imported. ${ }^{3}$

Sometimes the "seconds" are the verdicts from consumers on which product variations are good or bad; that is, when a firm puts products on the market it does not know ex ante which variations (e.g., color, cut, etc.) will be viewed as inferior. These seconds are (ex post) production mistakes, just like a bad apple, and are sold at a lower price in separate markets: at outlets (e.g., Neiman Marcus' Last Call Clearance Centers) or to off-price retail. "[Off-price retail] companies take advantage of overruns, canceled orders, and forecasting mistakes made by their counter-parts in the full-price retail sector" (Wikinvest 2017). ${ }^{4,5}$ The amount of overstock is not small as an IHL study estimated that " $\$ 1.5$ trillion of merchandise annually is in an overstock position" (Market Wired, 2012). There is a developed market for the exporting of the overstocks as producers may require that the overstocks be exported (AML , 2012). ${ }^{6}$ While the timing of the sorting is not identical to agricultural products, the segmentation of the production into different quality markets is broadly the same.

When considering an oligopolistic market instead of a perfectly competitive one, new effects result from a common per-unit charge as firms can alter both their production and export decision, and react to their rivals. ${ }^{7}$ For example, a firm that exports more of its low-quality product, gets a higher return on its home high-quality product, but cannibalizes its high-quality sales in the export market. But, if it faces more competition in the export market, it shifts some of this cannibalization onto its rivals as well. This raises the question

\footnotetext{
${ }^{2}$ Typing into google "Factory seconds..." a, b, c etc. completes with many products.

${ }^{3}$ On their web page April 2017 (http://www.sierratradingpost.com/2nds $\sim$ g $2314 /$ ): imported seconds include espresso machines, hiking bags, boots, jackets and dresses.

4 "When a major label like Polo Ralph Lauren (RL) miscalculates consumer preferences and over-produces a product, it will send the excess inventory to T.J. Maxx at a huge discount" (Wikinvest 2017). "Retail is a tricky business - consumers are finicky and even the best designers and retail professionals make mistakes sometimes about trends, colors and other design aspects, or miscalculate demand for a particular item..." (Handshake 2015). Returning to the classic apple story, the color may be "off" because of a bad dye lot.

${ }^{5}$ Off-price retailers include TJ/K Maxx/Marshalls (2500 stores worldwide) with $\$ 33$ billion in revenue, Ross Stores (1253 stores, $\$ 12$ billion in revenue), Burlington Coat factory (591 stores, $\$ 5$ billion in 2013).

${ }^{6}$ The company, AAA Closeout Liquidators, exports Gucci, L'oreal, Nike, Puma, Guess and Prada seconds (http://aaacloseout.com/categeories-item/export/)

${ }^{7}$ Even in the competitive equilibrium the Alchian-Allen effect would seem to require perfectly elastic supply, else changes in export quantities in response to the per-unit charge would change domestic consumption, relative prices, etc. and lead to interaction between the markets.
} 
of whether the Alchian-Allen effect exists in oligopolistic markets. If the effect does not exist under certain conditions, then empirical tests for it may be jointly testing market structure as well. This linking of markets also affects consumers. For example, as is well known, with increasing marginal cost, an oligopolistic firm that starts to export harms home consumers.

To examine these questions, a model with Cournot firms, instead of perfect competition, exporting from multiple countries is examined. Consumers are modeled with the standard approach (Mussa and Rosen, 1978; Tirole, 1988): they have unit demand but are heterogeneous in their preferences for quality. Starting with monopoly in autarky as a benchmark in Section 3), it is found that increasing the quality for the low-quality good (e.g., through minimum quality standards), could reduce production. The reason turns on the marginal buyer of high quality, who determines the price for high quality. This buyer is indifferent between buying high and low quality. Thus, holding constant output, an increase in the value of low quality, while it increases the price for low quality, it increases the marginal high-quality buyer's value for low quality even more. This is because the price for low quality is determined by the marginal buyer of low quality, who has a smaller value from the increase in quality than the marginal high-quality buyer. Thus, to keep the marginal buyer of high quality buying high quality, the price of high quality must fall. The firm in response may reduce output to offset the decrease in the high quality price. As a result, an increase in the value of low quality could reduce the firm's profit. Surprisingly, this also decreases consumer surplus. The finding in models of quality discrimination (Mussa and Rosen, 1978) that a monopolist enlarges the quality spectrum compared to the social optimum, may drive the profit result, but the consumer welfare effect is less clear. Of course, the classic monopoly models like Mussa and Rosen (1978) assume the firm has complete control over the quality levels, but as the above real world examples show, this is not always true. Finally, it is shown that an increase in the fraction of lower quality can induce the firm to increase output.

The model is then expanded in Section 4 to allow the firm to export into a market in which it competes with $n-1$ other firms, each a monopoly in their own country. Because each firm has three choices (total production, fraction of high quality to export, fraction of low 
quality to export), any asymmetry quickly makes deriving a closed form solution intractable. To alleviate this problem, it is first assumed the export market is scaled by a parameter $k$ relative to the producing countries. That is, the willingness-to-pay is scaled up or down by $k$, which implies the relative willingness-to-pay for higher quality, or "quality upgrading" (Johnson and Myatt, 2006), is also scaled by $k$. It is found that the fraction of high quality exported actually increases in transportation costs if the export market's willingness-to-pay for higher quality is greater than the domestic (Lemma 1). More importantly, shipping the good apples does not hold if the export market's willingness-to-pay for higher quality is sufficiently smaller (Proposition 1): an increase in the per-unit charge decreases the quantity demanded of high quality relative to low quality. Thus, empirically testing for the shipping the good apples may be jointly testing for the competitive market structure.

The intuition is that though exporting another bad apple also reduces the price for the good apple in the export market, it also raises the price in the domestic market: the relative price mark-up across markets are what matter. The key, then, is in which market consumers' willingness-to-pay for higher quality is greater. For $k<1$ it is relatively smaller in the export market, and so the firm earns a higher return keeping the high quality at home. However, the critical feedback is through the production decision as the per-unit charge decreases output. If, instead, output was held constant, then shipping the good apples always occurs (Lemma 3). Thus, shipping the good apples may occur in the very short-run, but not the long-run. Finally, even when the relative quantity demand for high quality decreases, the price of high quality relative to low quality always decreases (Proposition 2). Thus, there may be empirical evidence for market power when these two effects both decrease.

As the number of firms $(n)$ becomes large, the possibility there could be shipping the "bad" apples disappears (Proposition 3). However, the reason turns not on it being perfectly competitive in the limit but rather the opportunity cost in the domestic market for each monopolist: as $n$ becomes large so much low quality is exported that it is no longer profitable to export high quality. That is, there is no shipping the "bad" apples because there is no change in the amount of high quality shipped. To test this intuition, the model is then 
generalized in Subsection 5.0.1 to allow for $m$ firms within each of the $n$ producing countries and then the possibility of shipping the bad apples does not disappear as the number of firms within each country becomes large.

It may be conjectured that the shipping the bad apples result holds partly because the export market also has a lower average willingness-to-pay (e.g., is poorer). To show this is not true, a variation is considered in Subsection 5.1, in which the scale $(k)$ is for low quality only. That is, all markets have the same demand for high quality, but the export market's demand for low quality differs by $k$. So now $k>1$ means the export economy has a higher willingness-to-pay on average, but a lower willingness-to-pay for higher quality. If the key for shipping the bad apples is the willingness-to-pay for higher quality rather than on average, then shipping the bad apples should now occur when $k>1$ instead of $k<1$, and, indeed, it does (Proposition 4). Otherwise, the main results are unchanged.

Turning to welfare, domestic consumer surplus always increases with exporting (Proposition 6), regardless of whether or not there is shipping the good apples, nor how the export country is scaled (Proposition 7). That is, despite the Seattle consumers' lament, in an oligopolistic model they would benefit from shipping the good apples. This is true even though marginal cost of production is constant (so in a one good world exporting would have no effect on consumer surplus). It is perhaps even more surprising given that with convex costs, exporting reduces domestic consumer surplus. The intuition is that the firm is constrained by its quality mix and, as is well known, consumer surplus is convex in output: the benefit from a unit increase is greater than the loss from a unit decrease. The firm effect means that if it increases the fraction exported of one type, it decreases the other. Changes in transportation costs create this trade-off, and since high quality is valued more, if its exchange rate for low is less than one (but not too much less), which depends on how much production increases, surplus can increase. As these values also determine relative prices, the exchange satisfies the condition. Consumer surplus is then convex in transportation costs, reaching a minimum when the firm exports quality in the same proportion as at home, which equals the autarky level. 
The effect of an increase in the ad valorem tariff is examined in Section 7. Hummels and Skiba (2004) show that with strictly positive per-unit charges, an increase in the ad valorem tariff always reduces the quantity demand for high quality relative to low quality. The effect holds here as well (Proposition 8). Interestingly, it holds here even when the per-unit charge is zero, while in a competitive market it would have no effect (Hummels and Skiba, 2004). The presence of a positive ad valorem tariff also means that an increase in the per-unit charge may, contrary to Proposition 1 , decrease the relative quantity demanded of high quality even when the export market has higher willingness-to-pay for higher quality, that is, when $k>1$ in addition to when $k<1$. Finally, it is shown that trade again increases domestic consumer surplus with an ad valorem tariff (Proposition 9).

The model is then extended to consider differing fraction of seconds across countries. The introduction of asymmetry yields excessive lengthy closed-form solutions, making comparative statics limited. However, these and numerical analysis finds no novel effects.

\subsection{Related Literature}

The analysis in this paper is related to several other strands of work. There is an extensive literature of multiproduct quality competition in which firms choose which qualities to sell, while here the "seconds" are a byproduct. Gal-Or (1983) first took the quality model Mussa and Rosen (1978) to an oligopoly setting and that was extended by De Fraja (1996), Johnson and Myatt (2006), Johnson and Myatt (2015) and others. For the most part these papers do not consider the role of international trade (multiple markets), "seconds," and trade cost beyond the effect of increasing (doubling) the market size through trade and so the issue of how to allocate high quality across markets is not considered. There has been work in international trade examining quality choice These works have primarily examined single quality choice (Park (2001) and Zhou, et al (2002) and papers since). An exception is Ries (1993) who considers the effect of VERs on the profits (probably a positive effect) and quality

choice (no effect) on exporters with an absolute advantage in low-quality products. Although a model of (symmetric) horizontal rather than vertical differentiation, Chisholm and Norman 
(2012) examine product selection and export choice in the Brander and Krugman (1983) setting of reciprocal dumping with trade costs (but not in the Brander and Spencer (1985) setting of third country). ${ }^{8}$ There are two firms (one in each country) and two symmetric products (same quality) that they can produce and export and the primary focus is the effect of trade costs on product choice and welfare.

\section{Environment}

The model follows a standard structure: one country without production that imports only and $n$ producing countries. In each producing country there is, as in Brander and Spencer (1985), a single firm with a monopoly position at home (so can prevent re-importation), but it competes with the other $n-1$ firms in the $n+1^{\text {th }}$ country. In subsection 5.0.1 this assumption is relaxed so there are $m \geq 1$ firms in each country, where it is straightforward to construct examples in which the export price is greater than the domestic price so reimportation is not an issue. Location is indicated by subscript, with the representative firm (and country) denoted $d$ (domestic), the others with $f$ (foreign), and the export market country with $x$. Each firm produces a good of which a fraction $z$ is a "second," that is, a lower quality version of the good. This may be the result of the firm's failure to forecast which variations of a product will be viewed as inferior. For example, a firm may offer $m$ colors of a shirt, but consumers as a group view that $z$ of those colors are of lower quality like an ugly apple, or the color from a certain dye lot that is slightly different. ${ }^{9}$ Superscript $H(L)$ indicates the high (low) quality version of the good.

\footnotetext{
${ }^{8}$ See also Eckel and Neary (2010) and citations therein for other work examining product selection in international trade. Unlike Eckel and Neary (2010), almost all of the papers in this literature use monopolistic competition rather than oligopolistic, which allows for strategic interaction.

${ }^{9}$ While colors are normally thought of as horizontal dimension, as Cremer and Thisse (1991) note, horizontal differentiation is a special case of vertical differentiation. An expedient way to model this is to assume $y$ colors on a Salop circle and to let transport cost be zero (as done in, e.g., Rey and Tirole (1986)) with $z y((1-z) y)$ of the colors having quality $s^{L}\left(s^{H}\right)$, so that any two 'high' quality colors generate the same utility for a given consumer with consumers still differing in $\theta$.
} 


\subsection{Consumers}

Consumers are model with the standard approach (Mussa and Rosen, 1978; Tirole, 1988). In each country there is a mass of consumers with a population normalized to one. Each consumer has unit demand. Consumers have a higher willingness-to-pay for higher quality but are heterogeneous in their willingness-to-pay for higher quality. Specifically, each consumer has value $\theta$ for a good of quality $s^{j}, j \in\{H, L\}$, with $\theta$ distributed uniformly on $[0,1]$, so $\theta$ represents the consumers marginal willingness-to-pay for a unit increase in quality. That is, surplus for the consumer is $U=\theta s-p$ if they buy, zero else. For consumer $\theta$ their marginal willingness-to-pay for the higher quality good is $\theta\left(s^{H}-s^{L}\right)$, so a higher $\theta$ also has a higher marginal willingness-to-pay for an increase in quality.

As firms compete in quantities, consider the market clearing prices given $Q^{H}$ and $Q^{L}$ high-quality and low-quality units on the market $\left(Q^{H}+Q^{L}<1\right)$. The highest $\theta$ consumers buy the high quality units since they are willing to pay more for the higher quality. Then, the marginal buyer of high quality $\left(\theta^{H}\right)$ is defined by $\theta^{H}=1-Q^{H}$. The remainder $Q^{L}$ units go to the next highest $\theta$ 's (since they have the next greatest willingness-to-pay). So, the marginal buyer of low quality $\left(\theta^{L}\right)$ is defined by $\theta^{L}=1-\left(Q^{H}+Q^{L}\right)$. This consumer must have positive surplus, so $P^{L}-s^{L} \theta^{L} \geq 0$. If this holds with strict inequality, then consumers with a lower $\theta$ would want to buy, so market clearing requires that

$$
P^{L}=s^{L}\left[1-\left(Q^{H}+Q^{L}\right)\right]>0 .
$$

Market clearing also requires that the marginal consumer of high quality must weakly prefer high quality over low quality (and lower $\theta$ prefer low quality). Thus, the market clearing price for high quality must satisfy

$$
s^{H} \theta^{H}-P^{H}=\left(s^{L} \theta^{H}-P^{L}\right) .
$$




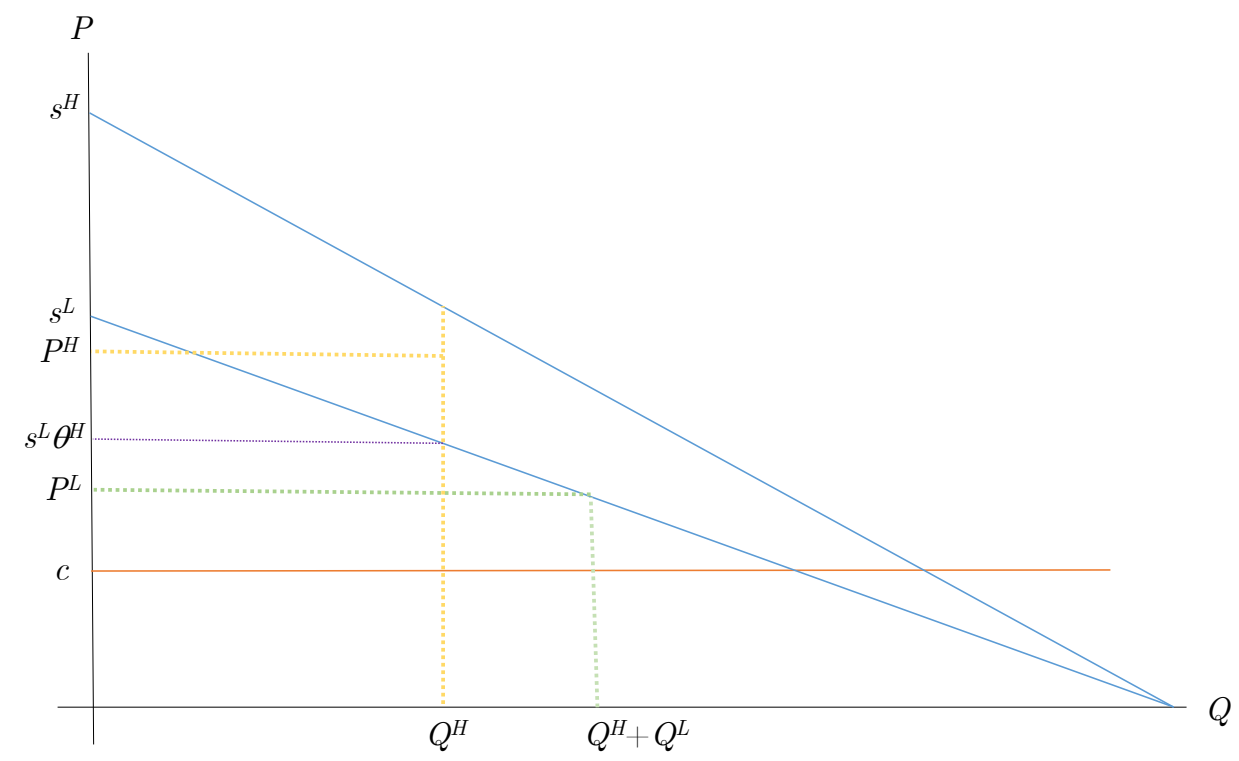

Figure 1: Market clearing prices

As market $Q^{H}=1-\theta^{H}$, then using (1), equation (2) can be written as

$$
P^{H}=s^{H}\left(1-Q^{H}\right)-s^{L} Q^{L} .
$$

There are interactions between the markets that will provide intuition for later results. ${ }^{10}$ First, if a unit of low quality is transformed into a unit of high quality, low-quality price does not change despite the decrease in low-quality supply (1). Second, another low-quality unit reduces the low-quality and the high-quality price (3) because the marginal high-quality consumer's surplus from buying low quality has increased. However, this does not affect the price premium for high quality. That is, subtracting $P^{L}(1)$ from $P^{H}(3)$ yields

$$
P^{H}-P^{L}=s^{H}\left(1-Q^{H}\right)-s^{L} Q^{L}-\left[s^{L}\left[1-\left(Q^{H}+Q^{L}\right)\right]\right]=\left(s^{H}-s^{L}\right)\left(1-Q^{H}\right) .
$$

Finally, another high-quality unit decreases the price of high quality more than when a low-quality unit was transformed to high quality because the low-quality price decreases.

\footnotetext{
${ }^{10}$ This analysis in a more general model is in Johnson and Myatt (2006).
} 


\section{$2.2 \quad$ Firm}

The representative firm produces $q_{d}$ units (subscript indicating "domestic"), $z_{d} q_{d}$ are low quality and $\left(1-z_{d}\right) q_{d}$ are high quality. The firm sells both to its own and to the export market where it competes with the other $n-1$ firms. Each unit exported incurs a per-unit charge/tariff/transport cost $t$, called transport cost for short. For this (and every) firm there are three decisions: how much to produce $\left(q_{d}\right)$, and how much to export of each type of good, high quality $\left(x_{d}^{H}\right)$ and low quality $\left(x_{d}^{L}\right)$ to the $n+1$ country. That is, $x_{d}^{L} z_{d} q_{d}$ of low-quality goods and $x_{d}^{H}\left(1-z_{d}\right) q_{d}$ high-quality goods are exported and so $\left(1-x_{d}^{H}\right)\left(1-z_{d}\right) q_{d}$ of the high quality remains in the domestic market, and similarly for low quality. The $n-1$ other producing firms face an analogous problem and for the export market, total high quality $\left(Q_{x}\right)$ is the sum of the $n$ firms' exports.

Firms have strictly positive constant marginal cost of production $c$, transportation cost $t$ and disposal costs. To ensure a basis for production and trade, it is assumed that the value of the first low-quality unit is greater than the cost of production and transport: $s^{L}>c+t$. The values of the parameters are assumed such that the equilibrium is an interior solution, and the conditions are explicitly defined later. Disposal costs (or rather, free disposal is not assumed) are the cost a firm incurs to be sure that the disposed good is actually disposed and not sold elsewhere. ${ }^{11}$ They are assumed large enough so that the firm would not choose to dispose of low quality. Instead, it could be assumed that the firm cannot commit to destroying its low quality, in which case it sells all of its low quality. ${ }^{12}$ This is because, if it cannot to commit to observably destroy its low quality, then consumers would expect the firms not to destroy it and sell it "on the side," as it would obtain a positive price, not unlike

\footnotetext{
${ }^{11}$ As, Global Sources, a trade company in Hong Kong, puts it "Imagine one day you're walking down a busy street full of vendors... you notice something: your company's flagship product...is being sold by a random merchant that you've never met....These are the same bags you rejected in an earlier order...yet here they are for sale, still with your branding." Global Sources recommend hiring a third-party inspector to make sure seconds are not mixed in with firsts in shipments. In addition, "[a]lthough it may seem excessive, one of the best ways to ensure that rejected or defective products don't end up being sold is to destroy them..." Methods include industrial shredders and steam rollers. Destruction also requires monitoring ("...how can you be sure the factory actually destroys them?" Global Sources (2016)) adding further to disposal costs.

${ }^{12}$ Positive destruction costs (which could include the cost of bad PR, e.g., supermarkets throwing away food) or the ability of the firm to commit to observably destroy low quality is only required for some key comparative static results in the benchmark sections 3-3.1.
} 
the logic behind the Coase Conjecture. Appendix A extends the model to explicitly allow the firm this dynamic as well as explicitly deriving the destruction cost needed for the firm to not destroy low quality if the firm could commit to observably destroy low quality. For the firm, then, its profit is its high-quality revenue in the domestic market, low-quality revenue in the domestic market, high-quality revenue in the export market, low-quality revenue in the export market, less production costs and the per-unit transport cost of the export goods:

$$
P_{d}^{H} Q_{d}^{H}+P_{d}^{L} Q_{d}^{L}+P_{x}^{H} x_{d}^{H}\left(1-z_{d}\right) q_{d}+P_{x}^{L} x_{d}^{L} z_{d} q_{d}-c q_{d}-t\left(x_{d}^{H}\left(1-z_{d}\right) q_{d}+x_{d}^{L} z_{d} q_{d}\right)
$$

Using the price equations $(3,1),(5)$ can be written as domestic market revenue, plus export market revenue, less per-unit transport cost

$$
\begin{aligned}
& {\left[s_{d}^{H}\left(1-Q_{d}^{H}\right)-s^{L} Q_{d}^{L}\right] Q_{d}^{H}+s_{d}^{L}\left[1-\left(Q_{d}^{H}+Q_{d}^{L}\right)\right] Q_{d}^{L}} \\
& \quad+\left[s_{x}^{H}\left(1-Q_{x}^{H}\right)-s_{x}^{L} Q_{x}^{L}\right] x_{d}^{H}\left(1-z_{d}\right) q_{d}+s_{x}^{L}\left[1-\left(Q_{x}^{H}+Q_{x}^{L}\right)\right] x_{d}^{L} z_{d} q_{d} \\
& \quad-c q_{d}-t\left(x_{d}^{H}\left(1-z_{d}\right) q_{d}+x_{d}^{L} z_{d} q_{d}\right)
\end{aligned}
$$

Finally, using the values for $Q,(6)$ can be written as profit as a function of production and fraction of high and low quality exported:

$$
\begin{aligned}
& \pi_{d}\left(q_{d}, x_{d}^{H}, x_{d}^{L}\right)=\left[s_{d}^{H}\left(1-\left(1-x_{d}^{H}\right)\left(1-z_{d}\right) q_{d}\right)-s_{d}^{L}\left(1-x_{d}^{L}\right) z_{d} q_{d}\right]\left(1-x_{d}^{H}\right)\left(1-z_{d}\right) q_{d} \\
& \quad+s_{d}^{L}\left[1-\left(\left(1-x_{d}^{H}\right)\left(1-z_{d}\right) q_{d}+\left(1-x_{d}^{L}\right) z_{d} q_{d}\right)\right]\left(1-x_{d}^{L}\right) z_{d} q_{d} \\
& \quad+\left[s_{x}^{H}\left(1-\left[x_{d}^{H}\left(1-z_{d}\right) q_{d}+\sum_{f \neq d}^{n} x_{f}^{H}\left(1-z_{f}\right) q_{f}\right]\right)+s_{x}^{L}\left[x_{d}^{L} z_{d} q_{d}+\sum_{f \neq d}^{n} x_{f}^{L} z_{f} q_{f}\right]\right] x_{d}^{H}\left(1-z_{d}\right) q_{d} \\
& \quad+s_{x}^{L}\left[1-\left(\left[x_{d}^{H}\left(1-z_{d}\right) q_{d}+\sum_{f \neq d}^{n} x_{f}^{H}\left(1-z_{f}\right) q_{f}\right]+\left[x_{d}^{L} z_{d} q_{d}+\sum_{f \neq d}^{n} x_{f}^{L} z_{f} q_{f}\right]\right)\right] x_{d}^{L} z_{d} q_{d} . \\
& \quad-c q_{d}-t\left(x_{d}^{H}\left(1-z_{d}\right) q_{d}+x_{d}^{L} z_{d} q_{d}\right) .
\end{aligned}
$$




\section{Benchmark: Monopoly in autarky}

To establish a benchmark, consider a monopoly in autarky. The problem simplifies to only choosing output $q_{d}$ :

$$
\begin{aligned}
\pi_{d}\left(q_{d}\right)=\left[s_{d}^{H}(1\right. & \left.\left.-\left(1-z_{d}\right) q_{d}\right)-s_{d}^{L} z_{d} q_{d}\right]\left(1-z_{d}\right) q_{d} \\
& \left.+s_{d}^{L}\left[1-\left(\left(1-z_{d}\right) q_{d}+z_{d} q_{d}\right)\right]\right) z_{d} q_{d}-c q_{d}
\end{aligned}
$$

Maximizing (8) with respect to $q_{d}$ obtains

$$
q_{d}^{A}=\frac{1}{2} \frac{\bar{s}_{d}-c}{\left[\left(1-z_{d}\right) \bar{s}_{d}+z_{d} s_{d}^{L}\right]},
$$

where the superscript A denotes "Autarky" and $\bar{s}_{d}=\left(1-z_{d}\right) s_{d}^{H}+z_{d} s_{d}^{L}$ is the average value.

From (9), an increase in $s_{d}^{L}$ decreases $q_{d}^{A}\left(d q_{d}^{A} / d s_{d}^{L}<0\right)$ if $s^{H}$ is not too close to $c{ }^{13}$ This occurs partly because, holding output constant, though the low-quality price (1) increases, the high-quality price decreases (3). The high-quality price decreases because the marginal high-quality buyer values the increase in low quality more than the marginal low-quality buyer does (which determines the increase in the low quality). As the marginal high-quality buyer now would buy low quality, the high-quality price must decrease. As a result, the firm may reduce production. This result may be related to Mussa and Rosen (1978) finding that a monopolist expands the quality spectrum relative to the social optimum.

A second effect is that an increase in $z_{d}$ causes production to increase under a stronger condition than the one for $d q_{d}^{A} / d s_{d}^{L}<0: s^{H}$ must be further from $c$, and $z \leq 1 / 2$ (a sufficient but not necessary condition). ${ }^{14,15}$ The reason is partly driven by an increase in $z$ having no effect on the low-quality price (1), as total output is constant, but increases the high-quality price (3) as high-quality production decreases.

\footnotetext{
${ }^{13}$ From (9) the condition is $s^{H}>c\left(2-z_{d}\right) /\left(1-z_{d}\right)$. For example, if $z_{d}=.10$, and $c=.5$, then one needs $s^{H}>1$. There always exist an $s^{H}$ such that this is true even if there is free destruction.

${ }^{14}$ From (9) the condition is $s^{H}>\left[s^{L} z_{d}^{2}+2 c\left(1-z_{d}\right)\right] /\left(1-z_{d}\right)^{2}$, so if $d q_{d}^{A} / d z_{d}>0$, then $d q_{d}^{A} / d s_{d}^{L}<0$.

${ }^{15}$ Since low quality are "seconds" $z \leq 1 / 2$ seems a reasonable assumption. If $z \geq 1 / 2$, then in addition $s^{H}$ need be sufficiently greater than $s^{L}$.
} 


\subsection{Welfare in autarky}

Using the solution (9) for $q_{d}$ in the profit expression (8) yields profit as a function of the value for each type of quality $\left(s^{(\cdot)}\right)$ of which a fraction $z$ are of lower quality.

$$
\pi_{d}^{A}\left(s_{d}^{H}, s_{d}^{L}, z_{d}\right)=\frac{1}{4} \frac{\left[\bar{s}_{d}-c\right]^{2}}{\left[\left(1-z_{d}\right) \bar{s}_{d}+z_{d} s_{d}^{L}\right]}
$$

Not surprisingly, an increase in $z$ always decreases profit. However, an increase in $s^{L}$ could decrease the firm's profit if $s^{H}$ is sufficiently large and destruction costs are not too close to zero (though less than production costs) or if the firm cannot commit itself to destroy low-quality output (modeled in Appendix A). Examples of low destruction costs (a fraction of production costs) in which the firm's profit decreases in $s^{L}$ are in Example 1 below. ${ }^{16}$ In addition, the firm's profit is convex in $s^{L}$.

Turning to consumers, low-quality consumer surplus is the standard triangle with linear demand, $(1 / 2) s_{d}^{L}\left(Q_{d}^{L}\right)^{2}$. High-quality consumer surplus includes the standard triangle, $(1 / 2) s_{d}^{H}\left(Q_{d}^{H}\right)^{2}$, but also includes the price discount the marginal high-quality buyer must receive to induce them to choose high quality over low quality: $s_{d}^{L} Q_{d}^{H} Q_{d}^{L}$. Thus,

$$
C S\left(s_{d}^{H}, s_{d}^{L}, z_{d}\right)=\left[\frac{1}{2} s_{d}^{H}\left(Q_{d}^{H}\right)^{2}+s_{d}^{L} Q_{d}^{H} Q_{d}^{L}\right]+\frac{1}{2} s_{d}^{L}\left(Q_{d}^{L}\right)^{2} .
$$

As $Q_{d}^{H}=\left(1-z_{d}\right) q_{d}^{A}$ and $Q_{d}^{L}=\left(z_{d}\right) q_{d}^{A}$ and substituting for (9), obtains

$$
C S^{A}\left(s_{d}^{H}, s_{d}^{L}, z_{d}\right)=\frac{\left[\bar{s}_{d}-c\right]^{2}}{8\left[\left(1-z_{d}\right) \bar{s}_{d}+z_{d} s_{d}^{L}\right]} .
$$

Despite the price discount in the high-quality consumer surplus, consumer surplus is the standard linear demand result of half the monopolist's profit. Thus, even though output can be increasing in $z_{d}$, it does not offset the decrease in high quality: increasing $z_{d}$ always decreases consumer and total welfare. Also, consumer surplus is convex in $s^{L}$ and an increase in $s^{L}$ can decrease consumer surplus under the same conditions for profit to decrease.

\footnotetext{
${ }^{16}$ From (10), the condition specifically is $s^{H}>\left(2-z_{d}\right)\left(z_{d} s^{L}+c\right) / z_{d}\left(1-z_{d}\right)$.
} 


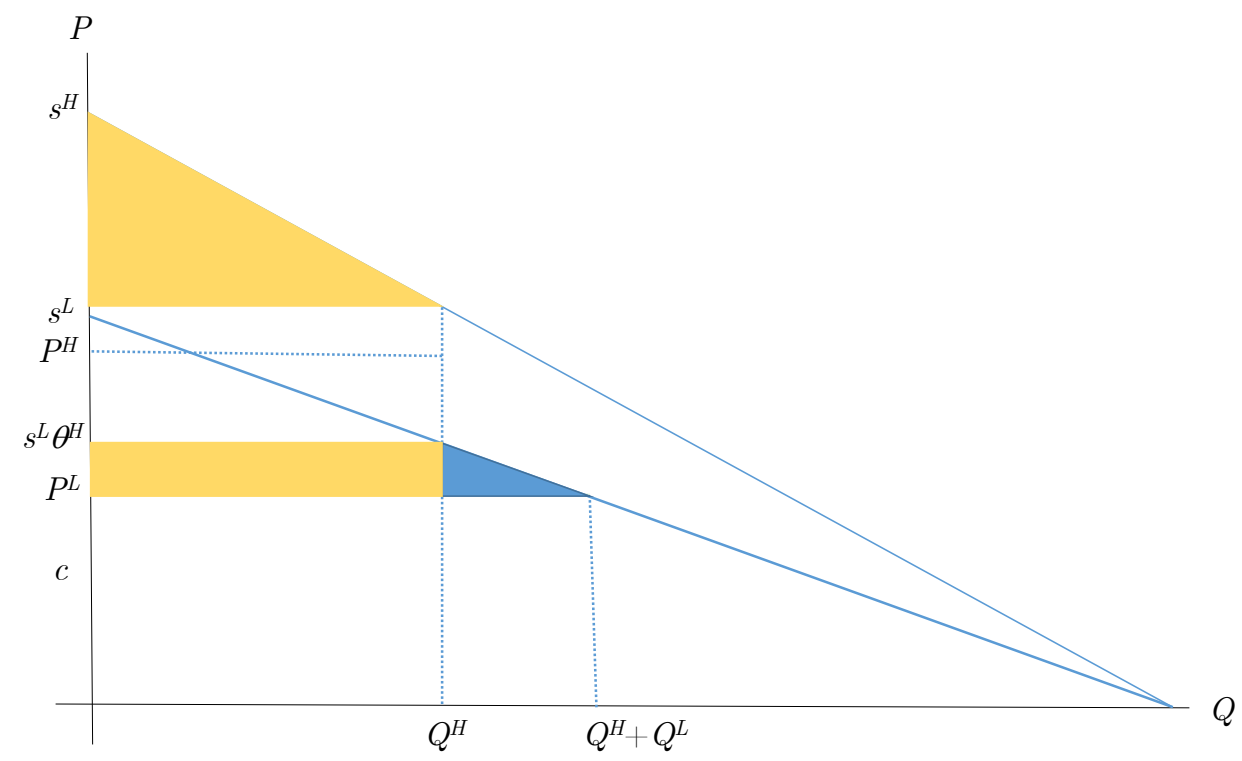

Figure 2: Consumer surplus low quality (blue), high quality (yellow)

Example 1 Welfare reducing increases in $s^{L}$. Let $s_{d}^{H} \geq 8, s_{d}^{L}=1.5, c=0.3$, and $z_{d}=1 / 9$. From (A.2), if unit destruction costs are $1 / 16(<c / 5)$, then an increase in $s_{d}^{L}$ reduces profit, consumer surplus and welfare. As another example, with $s_{d}^{H} \geq 6, s_{d}^{L}=1, c=1 / 8, z_{d}=1 / 15$, then if destruction costs are about $1 / 30$ of $s_{d}^{L}$, an increase in $s_{d}^{L}$ reduces welfare.

Alternatively, if sales occur in two stages, with the firm first selling high quality, and its lowquality output in the second, as modeled in Appendix A.2, then from the conditions derived in Appendix A.2, even if destruction costs are zero, then increases in $s^{L}$ reduce welfare in both examples as the firm does not destroy any of its low-quality output and $q_{d}^{A}$ is optimal.

\section{The $n+1$ country model}

There are now $n+1$ countries with the representative one denoted $d$ (domestic), the rival ones denoted $f$ (foreign) and $x$ for the export country (with no own-production). There is a single firm in each of the producing countries. The firms are monopolists in their own market but compete in quantities in the export market. The firm now chooses $q_{d}, x_{d}^{H}$ and $x_{d}^{L}$ (and analogously for its rivals) to maximize the sum of domestic high-quality market, 
domestic low-quality market, export high-quality market and export low-quality market less costs. As there are now $3 n$ choices (output, export fractions for $n$ firms), to obtain a closedform solution the fraction of low quality, marginal cost and "home" demands are assumed symmetric and the export market is assumed scaled by $k$. That is, $s_{d}^{H}=s_{f}^{H} \equiv s^{H}, s_{x}^{H}=k s^{H}$, $z_{d}=z_{f} \equiv z$, etc. The assumption that there is basis for trade (subsection 2.2) implies that $k s^{L}>c+t$. Subsection 5.0.1 allows for $m \geq 1$ firms in each country with no qualitative changes to the main results. Likewise, subsection 5.1 introduces asymmetry by having only low quality scaled $s_{x}^{L}=k s^{L}$, but $s_{x}^{H}=s^{H}$ and the key insights carry over. In Section 7, there is numerical analysis of asymmetric $z$ in a duopoly, but there are no new insights.

Given these assumptions, the firm's profit expression (7) becomes

$$
\begin{aligned}
& \pi_{d}\left(q_{d}, x_{d}^{H}, x_{d}^{L}\right)= \\
& \quad\left[s^{H}\left(1-\left(1-x_{d}^{H}\right)(1-z) q_{d}\right)-s^{L}\left(1-x_{d}^{L}\right) z q_{d}\right]\left(1-x_{d}^{H}\right)(1-z) q_{d} \\
& \quad+s^{L}\left[1-\left(\left(1-x_{d}^{H}\right)(1-z) q_{d}+\left(1-x_{d}^{L}\right) z q_{d}\right)\right]\left(1-x_{d}^{L}\right) z q_{d} \\
& \quad+\left[k s^{H}\left(1-\left[x_{d}^{H}(1-z) q_{d}+\sum_{f \neq d}^{n} x_{f}^{H}(1-z) q_{f}\right]\right)-k s^{L}\left[x_{d}^{L} z q_{d}+\sum_{f \neq d}^{n} x_{f}^{L} z q_{f}\right]\right] x_{d}^{H}(1-z) q_{d} \\
& \quad+k s^{L}\left[1-\left(\left[x_{d}^{H}(1-z) q_{d}+\sum_{f \neq d}^{n} x_{f}^{H}(1-z) q_{f}\right]+\left[x_{d}^{L} z q_{d}+\sum_{f \neq d}^{n} x_{f}^{L} z q_{f}\right]\right)\right] x_{d}^{L} z q_{d} \\
& \quad-c q_{d}-t\left(x_{d}^{H}(1-z) q_{d}+x_{d}^{L} z q_{d}\right) .
\end{aligned}
$$

Maximizing (13) with respect to $q_{d}, x_{d}^{H}$ and $x_{d}^{L}$ (and analogously for the foreign firms), then imposing symmetry obtains the Nash Equilibrium output and export fractions for the domestic firm (and likewise for the foreign firms)

$$
\begin{gathered}
q_{d}=\frac{n+3}{2(n+1)} \frac{\bar{s}-\frac{\kappa(n)}{(n+3) k} c-\frac{2 t}{(n+3) k}}{\left[(1-z) \bar{s}+z s^{L}\right]} \\
x_{d}^{H}=\frac{2}{\kappa(n)}-\frac{(1-k)}{\kappa(n)(1-z)} \frac{1}{q_{d}} \\
x_{d}^{L}=\frac{2}{\kappa(n)}-\frac{t}{\kappa(n) z s^{L}} \frac{1}{q_{d}},
\end{gathered}
$$


where $\kappa(n) \equiv 2+(n+1) k$. Note that $q_{d}$ equals the monopoly output for two markets if $k=1, n=1$ and $t=0$. The assumption that there is basis for trade $\left(k s^{L}>t+c\right)$ ensures $q_{d}>0,{ }^{17}$ and the fraction of low quality exported $\left(x_{d}^{L}\right)$ is positive for small enough $t$.

The fraction of high-quality exports, $x_{d}^{H}$, is clearly positive when $k \geq 1$. When, instead, $k<1$, zero production and per-unit transport cost $(c=0=t)$, are not sufficient for $x_{d}^{H}>0$ : it may not hold if $k$ is sufficiently close to zero and low quality is sufficiently similar to high quality $\left(s^{L} \rightarrow s^{H}\right)$, and there is sufficient competition ( $n$ large). Specifically, from 15, a necessary condition for $x_{d}^{H}>0$ (i.e., when $c=0=t$ ), is that $k$ is greater than

$$
\underline{k}_{x^{H}} \equiv \frac{(n+1) z s^{L}-2(1-z) \bar{s}}{\left[(1-z) \bar{s}+z s^{L}\right](n+1)}
$$

Note that $\underline{k}_{x^{H}}$ could be negative (i.e., $x_{d}^{H}>0 \forall k>0$ ), that with a single producing firmcountry, $x_{d}^{H}>0 \forall k$, and that $\underline{k}_{x^{H}}<1$. Even if $\underline{k}_{x^{H}}$ were maximized with respect to $s^{H}$ and $z$, three firms only requires $k>1 / 4$. More importantly, this critical $k$ is not binding for the main results. A sufficient critical $k$ can be obtained by noting that increases in $t$ decrease $x_{d}^{H}$ when $k<1$. As the efficiency condition puts an upper limit on $t\left(t<s^{L} k-c \equiv \bar{t}\right)$, this is substituted for $t$ in (15) to obtain a sufficient condition for $x_{d}^{H}>0$ : that $k$ is greater than

$$
\bar{k}_{x^{H}} \equiv \frac{(n+1)\left[z s^{L}+c(1-z)\right]-2(1-z)\left(\bar{s}-s^{L}\right)}{\left[(1-z) \bar{s}+z s^{L}\right](n+1)} .
$$

Note that $d x_{d}^{H}(\bar{t}) / d k>0, \bar{k}_{x^{H}}<1$ and $\underline{k}_{x^{H}}<\bar{k}_{x^{H}}$. For the results below, $\bar{k}_{x^{H}}$ is less than any critical $k$, i.e., for any $t<s^{L} k-c$, there are $k$ that satisfy the results and $x_{d}^{H}>0$.

Turning to comparative statics, output is, not surprisingly, decreasing in transportation cost. However, the fraction of high-quality exports is decreasing in output, all else equal, when $k>1$. Thus, when $k>1$ the fraction of high-quality exports is increasing in transportation costs, a type of super-shipping the good apples. To summarize

Lemma 1 When the export market is scaled by $k$ relative to the domestic markets, $d x_{d}^{H} / d t>$ 0 iff $k>1$ : as per-unit transport cost increases, the fraction of high-quality good exported

\footnotetext{
${ }^{17}$ Even the weaker condition that there is a basis for trade for expected quality $(k \bar{s}>t+c)$ is sufficient.
} 
increases if and only if the export market has a higher average willingness-to-pay.

While it may seem that the key to Lemma 1 is that the export market has a higher (average) willingness-to-pay, instead the key is that when $k>1$, the export market has a higher willingness-to-pay for higher quality or a "quality upgrade" (Johnson and Myatt, 2006). To make this point clear, in 5.1, the model is modified so that only the willingness-to-pay for low quality is scaled by $k$. In this case, when $k>1$, the export market still has the larger $\underline{\text { average }}$ willingness-to-pay, but a smaller willingness-to-pay for higher quality. As a result, it is when, instead, $k<1$ that $d x_{d}^{H} / d t>0$ (Lemma 4). This distinction may appear to be an overly fine point, but it is the underlying reason for the main results that follow.

Comparing the export fractions (15), the firm may export a greater fraction of its lowquality good - a type of shipping the bad apples.

Lemma 2 When the export market is scaled by $k$ relative to the domestic markets, $k \leq k^{*} \equiv$ $1-t \frac{1-z}{z s^{L}}$ iff $x_{d}^{H}<x_{d}^{L} ; \exists k<k^{*} \ni x_{d}^{H}>0 \forall t<s^{L} k-c \equiv \bar{t}$ : a greater fraction of low-quality goods are shipped if the export market's willingness-to-pay is sufficiently small.

The proof is in Appendix B.1. Example 2 below shows that not only can $x_{d}^{H}<x_{d}^{L}$, but the total amount of low quality exported can greater. The intuition for Lemma 2, like that of Lemma 1, turns on the relative willingness-to-pay for higher quality. For this reason, when the model is modified so that only the demand for low quality is scaled by $k$ in section 5.1, then $x_{d}^{H}<x_{d}^{L}$ when instead $k>1$ (Lemma 5) even though then the export market has a higher willingness-to-pay for average quality. Finally, if there is also a positive ad valorem tariff, then Lemma 2 must be modified, because then, even when the export market has a higher willingness-to-pay for average and higher quality, $k>1$, it is possible that $x_{d}^{H}<x_{d}^{L}$.

\section{$5 \quad$ Shipping the bad apples}

The Alchian-Allen effect is that the quantity demanded for high quality relative to lowquality goods, $Q_{x}^{H} / Q_{x}^{L}$ is increasing in per-unit transportation cost $t$. A sufficient condition 
is that the cross-price elasticity of each with respect to the composite good are equal for each consumer, which they are for the quasilinear preferences here. ${ }^{18}$ However, with strategic competition, the shipping the good apples theorem may not hold.

Proposition 1 (Shipping the bad apples) When the export market is scaled by $k$ relative to the domestic markets, if $k<\hat{k} \equiv\left(z s^{L}+(1-z) c\right) /\left[(1-z) \bar{s}+z s^{L}\right]<1$, then $d\left(Q_{x}^{H} / Q_{x}^{L}\right) / d t<0 ; \exists k<\hat{k} \ni x_{d}^{H}>0 \forall t<s^{L} k-c \equiv \bar{t}$ : if the willingness-to-pay in the export market is sufficiently small, then an increase in the per-unit transport cost decreases the relative quantity demanded for high quality in the export market. ${ }^{19}$

The proof is in Appendix B.2. Shipping the bad apples occurs when the export market has a sufficiently lower willingness-to-pay for higher quality and the modified model of section 5.1 supports this. That is, in that case, there can only be the shipping the bad apples when, instead, $k>1$ (Proposition 4), i.e., because there is a lower willingness-to-pay for higher quality even though higher willingness-to-pay on average. If, instead, there is also a positive ad valorem tariff, then Proposition 1 must be modified as there may be shipping the bad apples when $k>1$ as well as when $k<1$, that is, even when the export market has higher willingness-to-pay for average and higher quality (section 7.1).

Example 2 Consider the duopoly case $(n=2)$, with $s^{H}=2.2, s^{L}=1.8, z=0.3, k=$ $0.6, c=0.95, t=0.05, q_{d}=0.35$, with $x_{d}^{H}=0.1, x_{d}^{L}=0.45$, and $Q_{x}^{H} / Q_{x}^{L}=0.52$. A small increase in $t$ reduces this ratio.

The underlying force behind the shipping the bad apples is transportation cost's effect on the firm's output, which in turn effects the export fraction. This can be seen by examining (15), where holding output constant, as the per-unit transport cost increases, the fraction of low-quality exports decreases but the fraction of high-quality exports remains constant. That is, if there were no output response from an increase in the per-unit transport cost, shipping the good apples would always hold (or holds in the very short-run). ${ }^{20}$ To summarize,

\footnotetext{
${ }^{18}$ For complete derivations see Borcherding and Silberberg (1978) or Hummels and Skiba (2004) summary.

${ }^{19}$ Alternatively, for existence it can be shown that for $t$ and $c$ sufficiently small, $x_{d}^{H}>0$ at $\hat{k}$.

${ }^{20}$ This can also be seen with the best response functions of the export fractions in terms of outputs and export fractions of all rivals.
} 
Lemma $\left.3 \frac{\partial\left(Q_{x}^{H} / Q_{x}^{L}\right)}{\partial t}\right|_{q_{d}}>0$ : For fixed total production, there is always shipping the good apples in strategic competition.

The result of Lemma 3 is more general as it also holds for when only low quality is scaled (subsection 5.1) and with an ad valorem tariff in section 7.1.

With competitive markets, shipping the good apples occurs because the per-unit charge on both goods lowers the relative price of high-quality products and hence the increase in quantity demanded. A possible cause for Proposition 1, then, is that the pass-through on the charges differ so that the relative price of high quality increases. However, this is not the cause as the relative price always decreases with a per-unit transport cost.

Proposition 2 When the export market is scaled by $k$ relative to the domestic markets, $d\left(P_{x}^{H} / P_{x}^{L}\right) / d t<0$ : an increase in a per-unit transport cost, always decreases the price of the high-quality good relative to the low-quality good.

The proof is in Appendix B.3. This result extends to when only low quality is scaled (Proposition 5). Thus, part of the logic behind the shipping the good apples - that the relative price of high quality declines - extends to Cournot markets with linear demand. That the relative quantity demand of high quality could decrease at the same time (Proposition 1), potentially could be empirically investigated as a way of testing for market structure.

As the number of firm-country pair becomes large, the model does not quite become competitive in the limit as each firm retains its monopoly position at home. Despite this, as $n \rightarrow \infty$, there is only shipping the good apples.

Proposition 3 As the number of firm-country pairs becomes large, there is always shipping the good apples: $\left.\frac{d\left(Q_{x}^{H} / Q_{x}^{L}\right)}{d t}\right|_{n \rightarrow \infty} \geq 0$.

The proof is in Appendix B.4. The result relies heavily on firms being price-takers in the export market in the limit. As $n$ becomes large, the minimum $k$ such that there are positive exports of high quality, $\underline{k}_{x^{H}}$, becomes the maximum $k$ for shipping the bad apples, $\hat{k}$. Thus, for any $k<\hat{k}$, there are no high quality exports, so the relative demand for high quality 
cannot decrease. The reason $\underline{k}_{x^{H}}$ increases as $n$ becomes large is that the total amount of low quality exported to the export country becomes large driving down its and high quality's price so that it is not profitable to export high quality as the firm still has a monopoly at home: low quality drives out high quality. To eliminate this monopoly effect, in the next subsection the effect of more competition within each country is examined.

\subsection{1 $m$ firms in each $n$ producing countries}

There are now $m \geq 1$ firms in each country of the $n \geq 1$ producing countries. As there are now multiple firms in each country, subscript denotes country and firm within each country. For rotational ease let the representative firm be firm 1 in country $d(d, 1)$, so the profit expression for the representative firm becomes

$$
\begin{aligned}
& \pi_{d, 1}\left(q_{d, 1} x_{d, 1}^{H}, x_{d, 1}^{L}\right)= \\
& {\left[s^{H}\left(1-\sum_{i=1}^{m}\left(1-x_{d, i}^{H}\right)(1-z) q_{d, i}\right)-s^{L}\left(\sum_{i=1}^{m}\left(1-x_{d, i}^{L}\right) z q_{d, i}\right)\right] \times\left(1-x_{d, 1}^{H}\right)(1-z) q_{d, 1}} \\
& +s^{L}\left[1-\left(\sum_{i=1}^{m}\left(1-x_{d, i}^{H}\right)(1-z) q_{d, i}+\sum_{i=1}^{m}\left(1-x_{d, i}^{L}\right) z q_{d, i}\right)\right]\left(1-x_{d, 1}^{L}\right) z q_{d, 1} \\
& +\left[k s^{H}\left(1-\left(\sum_{i=1}^{m} x_{d, i}^{H}(1-z) q_{d}+\sum_{f \neq d}^{n} \sum_{i=1}^{m} x_{f, i}^{H}(1-z) q_{f, i}\right)\right)\right. \\
& \left.\quad-k s^{L}\left(\sum_{i=1}^{m} x_{d, i}^{L} z q_{d, i}+\sum_{f \neq d}^{n} \sum_{i=1}^{m} x_{f, i}^{L} z q_{f, i}\right)\right] \times x_{d, 1}^{H}(1-z) q_{d, 1} \\
& +k s^{L}\left[1-\left(\sum_{i=1}^{m} x_{d, i}^{H}(1-z) q_{d, i}+\sum_{f \neq d}^{n} \sum_{i=1}^{m} x_{f, i}^{H}(1-z) q_{f, i}\right.\right. \\
& \left.\left.\quad+\sum_{i=1}^{m} x_{d, i}^{L} z q_{d, i}+\sum_{f \neq d}^{n} \sum_{i=1}^{m} x_{f, i}^{L} z q_{f, i}\right)\right] \times x_{d, 1}^{L} z q_{d, 1} \\
& -c q_{d, 1}-t\left(x_{d, 1}^{H}(1-z) q_{d, 1}+x_{d, 1}^{L} z q_{d, 1}\right) .
\end{aligned}
$$

Maximizing (18) with respect to $q_{d, 1}, x_{d, 1}^{H}$ and $x_{d, 1}^{L}$ (and analogously for the other firms), then imposing symmetry obtains the Nash Equilibrium output and export fractions for the 
domestic firm 1 (and likewise for the other firms):

$$
\begin{gathered}
q_{d}=\frac{m(n+1)+2}{(m+1)(n m+1)} \frac{\bar{s}-\frac{\kappa(n, m)}{(m(n+1)+2) k} c-\frac{(m+1)}{(m(n+1)+2) k} t}{\left[(1-z) \bar{s}+z s^{L}\right]} \\
x_{d}^{H}=\frac{m+1}{\kappa(n, m)}-\frac{(1-k)}{\kappa(n, m)(1-z)} \frac{1}{q_{d}} \\
x_{d}^{L}=\frac{m+1}{\kappa(n, m)}-\frac{t}{\kappa(n, m) z s^{L}} \frac{1}{q_{d}},
\end{gathered}
$$

where $\kappa(n, m) \equiv(m+1)+(n m+1) k$.

From $(19,20)$ there is no change in Lemma 1 - when $k>1$ an increase in $t$ increases the fraction of high quality exported nor in Proposition 1: if $k<\hat{k}$, then an increase in $t$ causes the shipping of "bad" apples. Likewise, $q_{d}>0$ and for sufficiently small $t, x_{d}^{L}>0$. The necessary condition (when $t=c=0$ ) on $k$ for high-quality export, however, does change:

$$
\underline{k}_{x^{H}}(m) \equiv \frac{(n m+1) z s^{L}-(1+m)(1-z) \bar{s}}{\left[(1-z) \bar{s}+z s^{L}\right](n m+1)} .
$$

As before, as $n \rightarrow \infty, k_{x^{H}}(m)=\hat{k}(c=0)$ : when there is a large number of competing countries there cannot be shipping the "bad" apples. In contrast, increasing the number of firms within each country does not have the same effect:

$$
\lim _{m \rightarrow \infty} \underline{k}_{x^{H}}(m)=\hat{k}(c=0)-\frac{(1-z) \bar{s}}{n\left(\bar{s}+z s^{L}\right)} .
$$

The reason is that increasing the number of firms within a country reduces the return to high-quality apples in the domestic market, so that in the "bad" region it is still profitable to ship good apples and so the relative demand can still decrease. To put it differently, in the competitive limit a producing country there can still be shipping the "bad" apples because of the competitive supply response to the increase in $t$.

Turning to the sufficient condition on $k$, deriving $\bar{k}_{x^{H}}$ in this case is intractable. However, 
$\bar{k}_{x^{H}}$ can be derived for zero cost of production $(c=0)$ :

$$
\bar{k}_{x^{H}}(m, c=0) \equiv \frac{(n m+1) z s^{L}-(1+m)(1-z)^{2}\left(s^{H}-s^{L}\right)}{\left[(1-z) \bar{s}+z s^{L}\right](n m+1)} .
$$

Making the number of firms within each country large confirms the effect found with the necessary condition: there still can be the shipping of "bad" apples with competitive firms:

$$
\lim _{m \rightarrow \infty} \bar{k}_{x^{H}}(m, c=0)=\hat{k}(c=0)-\frac{(1-z)^{2}\left(s^{H}-s^{L}\right)}{n\left(\bar{s}+z s^{L}\right)} .
$$

Finally, for an unbalanced number of firms (e.g., one firm in country 1 and $m$ in country 2), a closed-form solution becomes intractable even with just two countries. Numerical analysis over a large range of parameter values suggests that this case has no new effects.

\subsection{Alternative specification: asymmetric scaling}

Returning to when there is one firm in each of the $n$ producing countries, now only low demand is scaled by $\hat{k}$ and high demand is identical across markets. That is, $s_{x}^{H}=s^{H}$. However, the low demand is still scaled: $s_{x}^{L}=k s^{L}, k<s^{H} / s^{L}$. The optimization problem for the representative firm changes only slightly to

$$
\begin{aligned}
& \pi_{d}\left(q_{d}, x_{d}^{H}, x_{d}^{L}\right)= \\
& \quad\left[s^{H}\left(1-\left(1-x_{d}^{H}\right)(1-z) q_{d}\right)-s^{L}\left(1-x_{d}^{L}\right) z q_{d}\right]\left(1-x_{d}^{H}\right)(1-z) q_{d} \\
& \quad+s^{L}\left[1-\left(\left(1-x_{d}^{H}\right)(1-z) q_{d}+\left(1-x_{d}^{L}\right) z q_{d}\right)\right]\left(1-x_{d}^{L}\right) z q_{d} \\
& \quad+\left[s^{H}\left(1-\left[x_{d}^{H}(1-z) q_{d}+\sum_{f \neq d}^{n} x_{f}^{H}(1-z) q_{f}\right]\right)-k s^{L}\left[x_{d}^{L} z q_{d}+\sum_{f \neq d}^{n} x_{f}^{L} z q_{f}\right]\right] x_{d}^{H}(1-z) q_{d} \\
& \quad+k s^{L}\left[1-\left(\left[x_{d}^{H}(1-z) q_{d}+\sum_{f \neq d}^{n} x_{f}^{H}(1-z) q_{f}\right]+\left[x_{d}^{L} z q_{d}+\sum_{f \neq d}^{n} x_{f}^{L} z q_{f}\right]\right)\right] x_{d}^{L} z q_{d} \\
& \quad-c q_{d}-t\left(x_{d}^{H}(1-z) q_{d}+x_{d}^{L} z q_{d}\right),
\end{aligned}
$$

Maximizing (21) with respect to $q_{d}, x_{d}^{H}$ and $x_{d}^{L}$ (and analogously for the foreign firms), 
then imposing symmetry obtains the Nash Equilibrium output and export fractions for the domestic firm (and likewise for the foreign firms). As the small additional asymmetry results in significantly more complex expressions, the model is restricted to the duopoly case $(n=2)$.

$$
\begin{aligned}
q_{d} & =\frac{5}{6} \frac{\bar{s} \kappa(2)\left(s^{H}-k s^{L}\right)-2(1-k) s^{H} s^{L}-\frac{5 s^{H}+\kappa(2) s^{L}}{5}(\kappa(2) c+t)}{\left[(1-z) \bar{s}+z s^{L}\right] \kappa(2)\left(s^{H}-k s^{L}\right)-2(1-k) s^{H} s^{L}} \\
x_{d}^{H} & =\frac{2\left(s^{H}-s^{L}\right)}{5 s^{H}-\kappa(2) s^{L}}+\frac{(1-k) s^{L}}{\left(5 s^{H}-\kappa(2) s^{L}\right)(1-z)} \frac{1}{q_{d}} \\
x_{d}^{L} & =\frac{2\left[\left(s^{H}-s^{L}\right) \kappa(2) z+3(1-k) s^{H}\right.}{\left(5 s^{H}-\kappa(2) s^{L}\right) \kappa(2) z}+\frac{5(k-1) s^{L}-\left[5-\kappa(2) s^{L}\right] t}{\left(5 s^{H}-\kappa(2) s^{L}\right) \kappa(2) z} \frac{1}{q_{d}} .
\end{aligned}
$$

From (23), increases in transportation costs increase the fraction of high quality exported only when the export market's average willingness-to-pay is less than the domestic market's $(k<1)$, the reverse of Lemma 1 (as $5 s^{H}-\kappa(2) s^{L}>0$ since $\left.k<s^{H} / s^{L}\right)$ :

Lemma 4 In a duopoly with only the export market low-quality demand scaled by $k$ relative to the domestic markets, $d x_{d}^{H} / d t>0$ iff $k<1$ : as per-unit transport cost increases, the fraction of high-quality good exported increases if and only if the export market has a lower average willingness-to-pay.

Unfortunately, a comparison of the export fractions (23) is not as tractable as previously, but a precise result is obtained when transport cost $(t)$ is set to zero. In this case, only when the export market's average willingness-to-pay is higher, could a greater fraction of low quality be exported, while in Lemma 2 it is when the average is lower. Specifically, substituting (22) for $q_{d}$ in (23), letting $t=0$ and differencing the export fraction obtains:

Lemma 5 In a duopoly with only the export market low-quality demand scaled by $k$ relative to the domestic markets, if $t=0$, then $k \geq 1$ iff $x_{d}^{H}<x_{d}^{L}$ : when the per unit tariff is zero, a greater fraction of low-quality goods are shipped if the export market willingness-to-pay is sufficiently large.

While a condition for $t>0$ could not be obtained, it is simple to derive examples in which for $t>0$ a greater fraction of low quality is exported even though the export market has a 
higher willingness-to-pay. For example, let $s^{H}=3, s^{L}=2, c=0.5=t, z=0.2$ and $k=1.2$. In this case calculating the export fractions obtain $x_{d}^{H}=0.327<0.411=x_{d}^{L}$.

Recall that in the baseline model, there is shipping the bad apples when the export economy has a lower willingness-to-pay than the domestic, that is when $k<1$ (Proposition 1). Here with only low quality scaled, it is the reverse: when $k>1$.

Proposition 4 (Shipping the bad apples) In a duopoly with only the export market lowquality demand scaled by $k$ relative to the domestic markets, if

$$
k>\tilde{k} \equiv \frac{\bar{s}^{2}-(1-z)\left(s^{H}-s^{L}\right)\left(z s^{L}+c\right)}{s^{L}\left[(1-z) \bar{s}+z s^{L}\right]}, \quad \tilde{k} \in\left(1, \frac{s^{H}}{s^{L}}\right)
$$

then $d\left(Q_{x}^{H} / Q_{x}^{L}\right) / d t<0$ : if the willingness-to-pay in the export market for low quality is sufficiently large, then an increase in the per-unit transport cost decreases the relative quantity demanded for high quality in the export market.

The proof is in Appendix B.5, and to be clear, it is a property of $\tilde{k}$ that $\tilde{k} \in\left(1, s^{H} / s^{L}\right)$, and not an assumption. As before, what is critical with asymmetric $k$ is that it implies that the export market has a lower relative willingness-to-pay for higher quality even though the export market's average willingness-to-pay is higher than the domestic market's.

Example 3 Let $s^{H}=2.2, s^{L}=1.8, z=0.3, k=1.1, c=0.95, t=0.05$. In this case, $q_{d}=0.46, x_{d}^{H} \approx 0.16$, and $x_{d}^{L} \approx 0.95$. A small increase in $t$ reduces this ratio.

Proposition 4, like Proposition 1, is driven by the changes in the production decision. That is, Lemma 3 holds here: if production is fixed, there is always shipping the good apples: $\left.\frac{\partial\left(Q_{x}^{H} / Q_{x}^{L}\right)}{\partial t}\right|_{q_{d}}>0$. Also, as with the baseline case (Section 4), the relative price of high quality decreases in $t$, so there is not a relative price increase causing the relative decrease in quantity demanded for high quality.

Proposition 5 In a duopoly with only the export market low-quality demand scaled by $k$ relative to the domestic markets, $d\left(P_{x}^{H} / P_{x}^{L}\right) / d t<0$ : an increase in a per-unit transport cost always decreases the price of the high-quality good relative to the low-quality good. 
The proof is similar to that of Proposition 2 and can be found in Appendix B.7.

\section{Welfare}

In previous work such as Brander and Spencer (1985), with constant marginal cost, trade has no effect on domestic consumption and so consumer welfare. However, with increasing marginal cost, trade reduces domestic consumer welfare. ${ }^{21}$ It may be intuited that the constraint that bad apples create for the firm may be similar to that of increasing costs and so trade harms domestic consumers, which is reflected in their "where are the good apples?" lament. For the baseline case, substituting the domestic quantity expressions, $Q_{d}^{H}=(1-z)\left(1-x_{d}^{H}\right) q_{d}$ and $Q_{d}^{L}=z\left(1-x_{d}^{L}\right) q_{d}$, into (11), consumer surplus with trade is

$$
\begin{gathered}
C S^{T}\left(s^{H}, s^{L}, z\right)=\left[\frac{s^{H}}{2}\left((1-z)\left(1-x_{d}^{H}\right) q_{d}\right)^{2}+s^{L}(1-z)\left(1-x_{d}^{H}\right) q_{d} z\left(1-x_{d}^{L}\right) q_{d}\right] \\
+\frac{s^{L}}{2}\left(z\left(1-x_{d}^{L}\right) q_{d}\right)^{2}
\end{gathered}
$$

Inserting the solutions for production (14) for $q_{d}$ and export fractions (15) for $x_{d}^{H}$ and $x_{d}^{L}$ into (24)and simplifying, yields

$$
C S^{T}\left(s^{H}, s^{L}, z\right)=C S^{A}\left(s^{H}, s^{L}, z\right)+\frac{\left(s^{H}-s^{L}\right)}{2 \kappa(n)^{2} s^{L}} \frac{\left[(k-1) z s^{L}+t(1-z)\right]^{2}}{(1-z) \bar{s}+z s^{L}}
$$

where $C S^{A}\left(s^{H}, s^{L}, z\right)$ is from (12).

When $k=1$ and $t=0$ (costlessly replicating the domestic market) or $k=k^{*}$ (when there is no distortion in the export mix), consumer surplus is the same as in autarky, otherwise

Proposition 6 When the export market is scaled by $k$ relative to the domestic markets, exporting increases domestic consumer surplus. ${ }^{22}$

The reason for the result is that domestic consumer surplus is convex in $t$ with a minimum at autarky, which occurs when $k=k^{*}$ and the firm exports at the same proportion as its

\footnotetext{
${ }^{21}$ As the firm could choose not to export, firm welfare increases with trade.

${ }^{22}$ As the firm is better-off, country welfare increases with trade.
} 
production fraction. This convexity reflects the firm's constraint - the fixed fraction of low quality it produces- and how the firm will distort in one direction or another the proportions as well as production, which affects domestic consumers. For example, if it produces more to export more high quality, then there will be more low quality at home even though there is less high quality. More specifically, consumer surplus is convex in $q_{d}^{H}$ and $q_{d}^{L}$ individually. Thus, starting at the autarky outputs $\left(k=k^{*}\right)$, increases in one $q$ increase consumer surplus at an increasing rate, while decreasing it decreases consumer surplus at a decreasing rate. That is, a one unit increase in price harms consumers less than they benefit from a one unit

decrease in price, as consumers can substitute to the other good. Since high quality has a greater effect on consumer surplus, for there to be convexity as one output increases, for a given decrease in high quality, the increase in low quality must be greater. And, in fact, an increase in $t$ for each unit it decreases domestic high quality, increases domestic low quality by $\bar{s} / s^{L}$. As a result, domestic consumer surplus is convex in $t$.

\subsection{Welfare with asymmetric scaling}

The results above suggest that the consumer welfare result should extend to the variation in the environment and it does. Inserting the equilibrium output $q_{d}(22)$ and export fractions $x_{d}^{H}$ and $x_{d}^{L}(23)$ into the consumer surplus expression (24), and simplifying obtains

$$
\begin{aligned}
& C S^{T}\left(s^{H}, s^{L}, z\right)=C S^{A}\left(s^{H}, s^{L}, z\right)+\frac{s^{H}-s^{L}}{2} \times \\
& \frac{\left[s^{L}(1-k) z\left[\left(s^{H}-s^{L}\right)\left((1-z) \bar{s}_{x}+k z s^{L}\right)-k s^{L} s^{H}\right]-(1-z)\left[(1-k) s^{H} s^{L} c+\left((1-z) \bar{s}+z s^{L}\right)\left(s^{H}-k s^{L}\right) t\right]\right]^{2}}{2 s^{L}\left[(1-z) \bar{s}+z s^{L}\right]\left[\left(s^{H}-s^{L}\right) \kappa\left[(1-z) \bar{s}_{x}+z k s^{L}\right]+3 k(1-k) s^{H} s^{L}\right]^{2}}
\end{aligned}
$$

where $\bar{s}_{x} \equiv(1-z) s^{H}+d k s^{L}$ is expected willingness-to-pay in the export market, $C S^{A}\left(s^{H}, s^{L}, z\right)$ is defined in (12), and recall that $\kappa(2)=2+3 k$.

Proposition 7 In a duopoly with only the export market low-quality demand scaled by $k$ relative to the domestic markets, exporting increases domestic consumer surplus. 
The difference has the properties as the main environment: e.g., if $t=0$, there is no effect, and if $t>0$, then the effect is positive even if $k=1$ (which was established above).

\section{Extensions}

\subsection{Ad Valorem Tariff}

Hummels and Skiba (2004) extended Alchian-Allen to examine the effect of an increase in the ad valorem tariff. They show that the relative demand for high-quality goods is decreasing in the ad valorem tariff rather than increasing as with the per-unit. However, if the per-unit transport cost is zero, then the ad valorem has no effect.

Let $v$ denote the ad valorem tariff so the firm's net price in the export market for high and low quality is $P_{x}^{H} /(1+v)$ and $P_{x}^{L} /(1+v)$. As another variable has been added $(v)$, to

obtain a closed-form solution, a duopoly is assumed $(n=2)$, though numeric analysis and intuition suggest the results hold for larger $n$. The domestic firm's profit now is

$$
P_{d}^{H} Q_{d}^{H}+P_{d}^{L} Q_{d}^{L}+\frac{P_{x}^{H}}{1+v} x_{d}^{H}(1-z) q_{d}+\frac{P_{x}^{L}}{1+v} x_{d}^{L} z q_{d}-c q_{d}-t\left(x_{d}^{H}(1-z) q_{d}+x_{d}^{L} z q_{d}\right)
$$

Substituting for the inverse demand functions and rival's choices in (26), profits is

$$
\begin{aligned}
& \pi_{d}\left(q_{d}, x_{d}^{H}, x_{d}^{L}\right)=\left[s^{H}\left(1-\left(1-x_{d}^{H}\right)(1-z) q_{d}\right)-s^{L}\left(1-x_{d}^{L}\right) z q_{d}\right]\left(1-x_{d}^{H}\right)(1-z) q_{d} \\
& \quad+s^{L}\left[1-\left(\left(1-x_{d}^{H}\right)(1-z) q_{d}+\left(1-x_{d}^{L}\right) z q_{d}\right)\right]\left(1-x_{d}^{L}\right) z q_{d} \\
& \quad+\frac{\left[k s^{H}\left(1-\left[x_{d}^{H}(1-z) q_{d}+x_{f}^{H}\left(1-z_{f}\right) q_{f}\right]\right)-k s^{L}\left[x_{d}^{L} z q_{d}+x_{f}^{L} z_{f} q_{f}\right]\right]}{1+v} x_{d}^{H}(1-z) q_{d} \\
& \quad+\frac{k s^{L}\left[1-\left(\left[x_{d}^{H}(1-z) q_{d}+x_{f}^{H}\left(1-z_{f}\right) q_{f}\right]+\left[x_{d}^{L} z q_{d}+x_{f}^{L} z_{f} q_{f}\right]\right)\right]}{1+v} x_{d}^{L} z q_{d} \\
& \quad-c q_{d}-t\left(x_{d}^{H}(1-z) q_{d}+x_{d}^{L} z q_{d}\right) .
\end{aligned}
$$

Maximizing (27) with respect to $q_{d}, x_{d}^{H}$ and $x_{d}^{L}$ (and analogously for the foreign firm), then imposing symmetry obtains, the Nash Equilibrium output and export fractions for the 
domestic firm, which are

$$
\begin{gathered}
q_{d}=\frac{5 \bar{s}-\frac{[3 k+2(v+1)] c}{6}-\frac{2(v+1) t}{5 k}}{\left[(1-z) \bar{s}+z s^{L}\right]} \\
x_{d}^{H}=\frac{2(v+1)}{\kappa_{v}(2)}-\frac{(1-k-v)}{\kappa_{v}(2)(1-z)} \frac{1}{q_{d}} \\
x_{d}^{L}=\frac{2(v+1)}{\kappa_{v}(2)}-\frac{t(v+1)}{\kappa_{v}(2) z s^{L}} \frac{1}{q_{d}},
\end{gathered}
$$

where $\kappa_{v}(2) \equiv 2(v+1)+3 k$. Note that output is clearly decreasing in the ad valorem tariff, but this effect is larger when there is a positive per-unit transport cost. If there is no ad valorem tariff $(v=0)$, then equations $(28,29)$ are the same as $(14,15)$ for $n=2$.

The ad valorem tariff appears explicitly in the export fractions, which does not occur with the per-unit charge, which makes determining the effect of an increase of the ad valorem tariff more complex and the parameter space needs to be restricted.

Lemma 6 In a duopoly, if the export market is scaled by $k$ relative to the domestic markets and either $t=0$ or $k<1+v$ or $k \rightarrow \infty$, then $d x_{d}^{H} / d v<0$, as the ad valorem tariff/transport cost increases, the fraction of high-quality good exported decreases when the per-unit transport cost is zero.

The proof is in appendix B.6. Numerical analysis suggests that the result holds for all $t$.

A positive ad valorem tariff has important effects on the comparative statics with respect to $t$. First, Lemma 1 is modified as the export economy could now have a lower relative willingness-to-pay (that is, $k<1$ as well as $k>1$ ), and an increase in $t$ still increases the fraction of high-quality good exported. Similarly, the condition for there to be shipping the bad apples from an increase in $t$ changes, as $\hat{k}$ in Proposition 1 becomes larger by $(1+v)$

$$
k<(1+v) \frac{z s^{L}+(1-z) c}{(1-z) \bar{s}+z s^{L}} .
$$

In fact, now there could be shipping the bad apples even when the export economy's willingness-to-pay is relatively larger than the domestic economy (i.e., $k>1$ ). The same for Lemma 2: it is now $k \leq(1+v)\left[1-t \frac{1-z}{z s^{L}}\right]$ and there could be $k>1$ in addition to $k<1$ when 
there is a greater fraction of low quality exported. However, Lemma 3 and (Proposition 2) are unchanged: holding production $(q)$ constant, there is always shipping the good apples, and the relative price of high quality is still always decreasing in the per-unit charge .

Returning to the effect of the ad valorem on the relative sales of high quality, to obtain an explicit result, the analysis is restricted to when the per-unit transport cost to zero. However, the result corresponds to Hummels and Skiba (2004) finding with competitive markets.

Proposition 8 In a duopoly, when the export market is scaled by $k$ relative to the domestic markets, if $t=0$, or $t \rightarrow 0, c \rightarrow 0$, then $d\left(Q_{x}^{H} / Q_{x}^{L}\right) / d v<0$ : if the per-unit transport cost is not too large, then an increase in the ad valorem decreases the relative quantity demanded for high quality in the export market.

The proof is in Appendix B.8. Numerical analysis suggests that the result is more general, that is, the relative quantity demanded for high quality decreases with $v$ even when $t>0$. One difference from previous work is that the result holds for $t=0$, that is, even when $t=0$, an increase in $v$ decreases relative quantity demanded for high quality, while in competitive markets (Hummels and Skiba, 2004) the effect does not exist with $t=0$. It is straightforward to show from (29) that holding output constant an increase in the ad valorem $v$ decreases relative high-quality quantity demanded, so the output-response does not play a critical role here. Finally, an increase in $v$ has no specific effect on the relative price of high quality: it can either decrease or increase. Some simple examples perhaps best capture this.

Example 4 Let $s^{H}=3, s^{L}=2, c=1, t=0.2, v=0.1, z=0.2, k=1.1$. In this case, the relative price of high quality is decreasing in the ad valorem tariff $v$. If production cost decrease to $c=0.5$, then relative price of high quality is increasing. In both examples, though, relative quantity demanded in high quality decreases.

Finally, the result that trade increases consumer surplus holds with positive ad valorem tariff. As before, we can solve for consumer surplus with trade. Substituting for (28) into 
the consumer surplus expression (11), obtains

$$
C S^{T}\left(s^{H}, s^{L}, z\right)=C S^{A}+\frac{\left(s^{H}-s^{L}\right)}{2 \kappa_{v}(2)^{2} s^{L}} \frac{\left[(1+v)\left[(k-1) z s^{L}+t(1-z)\right]-v z s^{L} k\right]^{2}}{(1-z) \bar{s}+z s^{L}}
$$

which is the expression in (25) roughly scaled by $v$. To summarize,

Proposition 9 In a duopoly, when the export market demand is scaled by $k$ relative to the domestic markets and there is an ad valorem tariff on exports, exporting increases domestic consumer surplus.

\subsection{Asymmetric rates of low quality}

Asymmetry between firms is now considered: differing fractions of bad apples $(z)$. Unfortunately, such asymmetry makes obtaining a closed-form solution difficult. To make the analysis tractable, the export economy is assumed the same as the domestic one $(k=1)$, marginal cost is set to zero $(c=0)$ and there are two firms $(n=2)$. The differing $z$ 's could also be interpreted as when one country has a cost, technological or institutional advantage. The domestic firm chooses $q_{d}, x_{d}^{H}, x_{d}^{L}$ to maximize

$$
\begin{aligned}
\pi_{d}\left(q_{d}, x_{d}^{H}, x_{d}^{L}\right)= & \left.s^{H}\left(1-\left(1-x_{d}^{H}\right)\left(1-z_{d}\right) q_{d}\right)-s^{L}\left(1-x_{d}^{L}\right) z_{d} q_{d}\right]\left(1-x_{d}^{H}\right)\left(1-z_{d}\right) q_{d} \\
& +s^{L}\left[1-\left(\left(1-x_{d}^{H}\right)\left(1-z_{d}\right) q_{d}+\left(1-x_{d}^{L}\right) z_{d} q_{d}\right)\right]\left(1-x_{d}^{L}\right) z_{d} q_{d} \\
& +\left[s^{H}\left(1-\left[x_{d}^{H}\left(1-z_{d}\right) q_{d}+x_{f}^{H}\left(1-z_{f}\right) q_{f}\right]\right)-s^{L}\left[x_{d}^{L} z_{d} q_{d}+x_{f}^{L} z_{f} q_{f}\right]\right] x_{d}^{H}\left(1-z_{d}\right) q_{d} \\
& +s^{L}\left[1-\left(\left[x_{d}^{H}\left(1-z_{d}\right) q_{d}+x_{f}^{H}\left(1-z_{f}\right) q_{f}\right]+\left[x_{d}^{L} z_{d} q_{d}+x_{f}^{L} z_{f} q_{f}\right]\right)\right] x_{d}^{L} z_{d} q_{d} \\
& \quad-c q_{d}-t\left(x_{d}^{H}\left(1-z_{d}\right) q_{d}+x_{d}^{L} z_{d} q_{d}\right),
\end{aligned}
$$

and its rival chooses $q_{f}, x_{f}^{H}, x_{f}^{L}$ to maximize the analogous expression. The equilibrium quantities cannot be presented in a short enough form for the margins, but are denoted $q_{d}^{D}$ 
and $q_{f}^{D}$, where the superscript D is for "Duopoly." The equilibrium export shares are

$$
\begin{aligned}
& x_{d}^{H, D}=\frac{8}{15}-\frac{2}{15} \frac{\left(1-z_{f}\right)}{\left(1-z_{d}\right)} \frac{q_{f}^{D}}{q_{d}^{D}} \quad x_{d}^{L, D}=\frac{8}{15}-\frac{2}{15} \frac{z_{f} q_{f}^{D}}{z_{d} q_{d}^{D}}-\frac{3}{15} \frac{t}{s^{L} z_{d} q_{d}^{D}} \\
& x_{f}^{H, D}=\frac{8}{15}-\frac{2}{15} \frac{\left(1-z_{d}\right)}{\left(1-z_{f}\right)} \frac{q_{d}^{D}}{q_{f}^{D}} \quad x_{f}^{L, D}=\frac{8}{15}-\frac{2}{15} \frac{z_{d} q_{d}^{D}}{z_{f} q_{f}^{D}}-\frac{3}{15} \frac{t}{s^{L} z_{f} q_{f}^{D}} .
\end{aligned}
$$

The comparative statics are as follows. The less efficient firm (the one with a greater fraction of bad apples $z$ ), sets a higher level of production so long as $z$ is not too high, $s^{L}$ is not too close to $s^{H}$ and $t$ is not too close to $s^{L}$. This results in a larger fraction of low quality exported for the less efficient firm, but also a smaller fraction of high quality exported. The firm in this case exports more than its more efficient rival, but less high quality. Despite the greater output, there is no Stackelberg-type advantage: profit is greater for the more efficient firm. When $z$ differs significantly, the country with greater $z$ can export proportionately more of the low-quality good, a type of comparative advantage.

Turning to consumers, the less efficient firm never has more high quality on the domestic market, despite its smaller export fraction. It is more likely to ship more of the bad apples when its disadvantage is greater, low quality has greater value, and transportation costs are lower. Total amount of the good can be greater on the less efficient domestic market, but despite this, consumers in the less efficient market have lower consumer surplus than those in the more efficient market primarily because the efficient market mix tilts to high quality. While consumer surplus is less in the country with the larger fraction of bad apples, in that country consumer surplus is still greater than with autarky.

\section{Conclusion}

Production runs suffer from inadvertent quality variation and firms must decide what to do with their lower quality output. A model of such firms competing strategically in an export market is examined. It is found that shipping the good apples -the classic result that an increase in a per-unit charge increases the relative demand for high quality - may not hold 
when the export market has a relatively lower willingness-to-pay for higher quality. (However, the classic result re-emerges if modified to the export demand has a higher willingness-topay for higher quality.) The key to shipping the good apples not holding is the production response to the per-unit charge because with fixed production, shipping the good apples always holds in this model. This suggests that empirically shipping the good apples may always be observed in the very short-run, but not always in the long-run. Finally, despite consumers complaining about the good apples being shipped, as a whole they are better off from trade.

There are several possible directions for future analysis. As introducing asymmetries make obtaining closed-form solutions and general analysis difficult, finding natural asymmetries that are tractable and provided novel insights would be good. One seemingly obvious possibility is to endogenize $z$, the rate of bad apples. The firms could invest up-front to reduce $z$. On the other hand, with a symmetric equilibrium, the endogenous $z$ 's should be identical and so it is not immediate what the possible insights could be. Of course, as countries are heterogeneous in technological ability, one could imagine differing cost of investment (or superior domestic institutions to make reducing $z$ less expensive, for example, Costinot (2009) models the ability to contract with suppliers depends on institutional quality. Yet, this would likely lead to differing $z$, which was already found to be intractable with even only two firms and, more importantly, with no novel insights. Another direction would be to consider the "reciprocal dumping" (Brander and Krugman, 1983) environment though this is not the environment typically associated with shipping the good apples. Yet, this extension might provide its own insights and a strategic effect from high $z$ might arise. Finally, this is a natural environment to examine minimum quality standards, ${ }^{23}$ most simply by the export market banning the importation of low quality or forcing an increase in the quality of seconds.

\footnotetext{
${ }^{23}$ Ronnen (1991), Crampes and Hollander (1995) and in international trade beginning with Boom (1995).
} 


\section{Appendix A Non-disposal of low quality}

This section examines two effects that would prevent the firm from disposing (destroying) low-quality goods: the firm's inability to commit to observably destroy the goods and the cost associated with destroying the goods.

\section{A.1 Deriving destruction costs}

In this subsection, the destruction (disposal) cost (possibly zero) needed to prevent the firm from destroying low-quality goods are derived. As noted before, these destruction costs need not be pecuniary as a firm destroying valuable goods could create a public outcry that is costly to the firm such as with supermarkets destroying unsold food. For example (Rico, 2015), the NFL stopped destroying the merchandise for the losing Super Bowl team in 1996, instead donating it to charity where it is exported to countries where it is "most needed." Specifically, assume after production is chosen $\left(q_{d}\right)$ and its cost incurred $\left(c q_{d}\right)$, there is a second stage in which the firm could choose to reduce its low-quality output in a way that is observable to consumers. That is, the firm chooses the amount of low quality, $q_{d}^{L}$, to maximize

$$
\begin{gathered}
\pi_{d}\left(q_{d}\right)=\left[s_{d}^{H}\left(1-\left(1-z_{d}\right) q_{d}\right)-s_{d}^{L} q_{d}^{L}\right)\left(1-z_{d}\right) q_{d} \\
+s_{d}^{L}\left[1-\left(\left(1-z_{d}\right) q_{d}+q_{d}^{L}\right)\right] q_{d}^{L}
\end{gathered}
$$

subject to its choice being less than or equal to the amount of low-quality goods available: $q_{d}^{L} \leq z_{d} q_{d}$. Differentiating A.1 with respect to $q_{d}^{L}$ yields

$$
-s_{d}^{L}\left(1-z_{d}\right) q_{d}-s_{d}^{L} q_{d}^{L}+s_{d}^{L}\left[1-\left(\left(1-z_{d}\right) q_{d}+q_{d}^{L}\right)\right]
$$

The last two terms are the marginal revenue in the low-quality market. The first term is the negative effect on the high-quality market. This negative effect arises because as you increase

$q_{d}^{L}$, you reduce the high-quality price by $s_{d}^{L}$ (because this how much the low-quality price 
decreases, which the high-quality price must decrease too to keep the marginal consumer buying high quality). Collecting terms and then substituting for $q_{d}^{A}(9)$, can be written as

$$
s_{d}^{L}\left(1-2 q_{d}\right)=s_{d}^{L}\left(1-\frac{\bar{s}_{d}-c}{\left[\left(1-z_{d}\right) \bar{s}_{d}+z_{d} s_{d}^{L}\right]}\right) .
$$

If expression (A.2) is non-negative, then the firm would not want to destroy any of its lowquality output. That is, so long as production is less than $1 / 2$, even if it could do costlessly, the firm would not choose to destroy some of its low quality. Thus, higher production costs, lower $s_{d}^{H}$, higher $s_{d}^{L}$, and lower $z_{d}$ (assuming $z \leq 1 / 2$ ) make the condition more likely met.

Specifically, if $c>z_{d}\left(1-z_{d}\right)\left(s_{d}^{H}-s_{d}^{L}\right)$, then the condition is met with zero disposal costs. Alternatively, if the marginal destruction cost is greater than $\left.s_{d}^{L}\left(1-2 q_{d}^{A}\right)\right)$, then the firm would not destroy any of its low-quality goods. The RHS of (A.2) is the destruction cost reported in the examples of subsections 3-3.1. Obviously, as the functions are concave, if disposal costs are just below this value the firm would only destroy an arbitrarily small fraction of the low-quality good. The necessary destruction cost for other market structures are derived analogously.

\section{A.2 Need for commitment for observable destruction}

In this subsection, a simple modification is made to the monopoly model of subsection 3 to show the "Coase conjecture" type of problem facing a firm that wants to destroy some of its low-quality output. That is, when the positive destruction costs are needed to prevent a firm from disposing any of its low quality as derived in section (A.1), even if destruction costs are zero, a firm without the ability to commit to observably destroy its output, may not. To this, modify the previous model so that the products are sold sequentially by type: in the first stage the firm first puts the high quality on the market, and in the second stage the firm puts the low quality on the market. This seems a natural extension as firms are observed putting their best product out first. In the second stage, the firm chooses the amount of low 
quality, $q_{d}^{L}$, to maximize

$$
\left.\pi_{d}^{L}\left(q_{d}^{L}\right)=s_{d}^{L}\left[1-\left(\left(1-z_{d}\right) q_{d}+q_{d}^{L}\right)\right]\right) q_{d}^{L}
$$

subject to its choice being less than or equal to the amount of low-quality goods available: $q_{d}^{L} \leq z_{d} q_{d}$. Differentiating A.3 with respect to $q_{d}^{L}$ yields

$$
-s_{d}^{L} q_{d}^{L}+s_{d}^{L}\left[1-\left(\left(1-z_{d}\right) q_{d}+q_{d}^{L}\right)\right]
$$

Noting that (A.3) is concave in $q_{d}^{L}$ and evaluating (A.4) at $q_{d}^{A}$, the expression (A.4) is positive so long as

$$
c \geq \frac{\left(1-z_{d}\right)\left(\left(3 z_{d}-1\right) s_{d}^{H}-3 z_{d} s_{d}^{L}\right)}{1+z_{d}} .
$$

Obviously, then, for all $z_{d} \leq 1 / 3$, the firm would want to put all of its low quality on the market for any $c \geq 0$. Further, if $s_{d}^{H} \leq 3 s_{d}^{L}$, then this holds for all $z_{d} \leq 1 / 2$. That is, the firm would be unable to dispose of any of its low quality under these conditions because it cannot commit to it. Specifically, even if $c<z_{d}\left(1-z_{d}\right)\left(s_{d}^{H}-s_{d}^{L}\right)$ from the previous section (A.1), the firm would not dispose of any of its low-quality product. (To be complete, the first stage must be checked, but not surprisingly, the derivative of high and low-quality profit (8), with respect to high-quality output is positive for any $c \geq 0$. $)^{24}$

\section{Appendix B Proofs}

\section{B.1 Proof of Lemma 2}

Lemma 2 When the export market is scaled by $k$ relative to the domestic markets, $k \leq k^{*} \equiv$ $1-t \frac{1-z}{z s^{L}}$ iff $x_{d}^{H}<x_{d}^{L} ; \exists k<k^{*} \ni x_{d}^{H}>0 \forall t<s^{L} k-c \equiv \bar{t}$ : a greater fraction of low-quality

\footnotetext{
${ }^{24}$ The purpose of this subsection was to show that with a lack of commitment a firm would sell all of its low quality when with commitment it would not (section A.1). If the condition on $z_{d}$ does not hold then the problem becomes more complicated as the firm in choosing its original production must take this into account.
} 
goods are shipped than high-quality goods if the export market is sufficiently weak.

Proof. The statement $k \leq 1-t \frac{1-z}{z s^{L}}$ iff $x_{d}^{H}<x_{d}^{L}$ follows directly from differencing 15 . To show there exists $k<k *$ with an interior solution for any $t<s^{L} k-c$, i.e., $x_{d}^{H}>0$ for all possible $t$, recall that $\bar{k}_{x^{H}}(17)$ is the minimum $k$ needed for $x_{d}^{H}>0$ when $t=s^{L} k-c \equiv \bar{t}$ (the highest per unit charge that meets the efficiency condition) and this $x_{d}^{H}$ is increasing in $k$. Solving for the $k^{*}$ when $t=\bar{t}$ (since this $t$ is a function of $k$ ), obtains $k^{*}(\bar{t})=z+c(1-z) / s^{L}$, which is greater than $\bar{k}_{x^{H}}$ :

$$
k^{*}(\bar{t})-\bar{k}_{x^{H}}=(1-z)^{2}\left(s^{H}-s^{L}\right) \frac{s^{L}(2+z(n+1))+(n+1)(1-z) c}{s^{L}(n+1)\left[(1-z) \bar{s}+z s^{L}\right]}>0,
$$

so there exist $k$ at $\bar{t}$ such that $x_{d}^{H}>0 . x_{d}^{H}$ is decreasing in $t$, so at $\bar{k}_{x^{H}} x_{d}^{H}$ is increasing (and so positive) for any $t<\bar{t}$. As $k^{*}$ is decreasing in $t$, for any $t<\bar{t}, k *>k^{*}(\bar{t})>\bar{k}_{x^{H}}$. So, for any $t<\bar{t}, x_{d}^{H}$ at $\bar{k}_{x^{H}}$ is positive and less than $x_{d}^{L}$.

\section{B.2 Proof of Proposition 1}

Proposition 1 When the export market is scaled by $k$ relative to the domestic markets, if $k<\hat{k} \equiv\left(z s^{L}+(1-z) c\right) /\left[(1-z) \bar{s}+z s^{L}\right]<1$, then $d\left(Q_{x}^{H} / Q_{x}^{L}\right) / d t<0 ; \exists k<\hat{k} \ni x_{d}^{H}>$

$0 \forall t<s^{L} k-c \equiv \bar{t}$ : if the willingness-to-pay in the export market is sufficiently small, then an increase in the per-unit transport cost decreases the relative quantity demanded for high quality in the export market

Proof.

$$
\frac{Q_{x}^{H}}{Q_{x}^{L}}=\frac{(1-z) x_{d}^{H} q_{d}}{z x_{d}^{L} q_{d}}=\frac{s^{L}\left[2(1-z) q_{d}(t)+k-1\right.}{2 s^{L} z q_{d}(t)-t}
$$

Differentiating with respect to $t$ yields

$$
\frac{d\left(Q_{x}^{H} / Q_{x}^{L}\right)}{d t}=\frac{2 s^{L}\left[(1-z) t+s^{L} z(1-k)\right]}{\left(2 s^{L} z q_{d}-t\right)^{2}} \frac{d q_{d}}{d t}+\frac{s^{L}\left[2(1-z) q_{d}+k-1\right.}{\left(2 s^{L} z q_{d}-t\right)^{2}},
$$

where from 14 ,

$$
\frac{d q_{d}}{d t}=\frac{-2}{2(n+1) k\left[(1-z) \bar{s}+z s^{L}\right]}
$$


Substituting in with 14 and B.1 and solving for $k$ yields

$$
\hat{k}=\frac{z s^{L}+(1-z) c}{(1-z) \bar{s}+z s^{L}} .
$$

The proof that there exists $k<k *$ with an interior solution for any $t<\bar{t}$, i.e., $x_{d}^{H}>0$ for all possible $t$, follows the proof for Lemma 2 . Recall $\bar{k}_{x^{H}}(17)$ is the minimum $k$ needed for $x_{d}^{H}>0$ when $t=\bar{t}$ and this $x_{d}^{H}$ is increasing in $k . \bar{k}_{x^{H}}$ is less than $\hat{k}$ :

$$
\hat{k}-\bar{k}_{x^{H}}=\frac{2(1-z)^{2}\left(s^{H}-s^{L}\right)}{(n+1)\left[(1-z) \bar{s}+z s^{L}\right]}>0,
$$

so there exist $k$ at $\bar{t}$ such that $x_{d}^{H}>0$ when $d\left(Q_{x}^{H} / Q_{x}^{L}\right) / d t<0 . x_{d}^{H}$ is decreasing in $t$, so at $\bar{k}_{x^{H}} x_{d}^{H}$ is increasing (and so positive) for any $t<\bar{t}$. As $\hat{k}$ is independent in $t$, for any $t<\bar{t}$, $\hat{k}>\bar{k}_{x^{H}}$. So, for any $t<\bar{t}, x_{d}^{H}$ at $\bar{k}_{x^{H}}$ is positive and less than $x_{d}^{L} \cdot{ }^{25}$

\section{B.3 Proof of Proposition 2}

Proposition 2 When the export market is scaled by $k$ relative to the domestic markets, $d\left(P_{x}^{H} / P_{x}^{L}\right) / d t<0$ : an increase in a per-unit transport cost, always decreases the price of the high-quality good relative to the low-quality good.

Proof.

$$
\frac{P_{x}^{H}}{P_{x}^{L}}=\frac{s^{H}\left(1-Q_{x}^{H}\right)-s^{L} Q_{x}^{L}}{s^{L}\left[1-\left(Q_{x}^{H}+Q_{x}^{L}\right)\right]} .
$$

Recalling that in the symmetric equilibrium $q_{i}=q_{d}, \forall i \in f$ so that $Q_{x}^{(\cdot)}=n q_{d}^{(\cdot)}$, the ratio simplifies to

$$
\frac{P_{x}^{H}}{P_{x}^{L}}=\frac{s^{H}(n+k+2) t n-2 n q_{d}(t)(\bar{s})}{s^{L}\left(2+k-2 q_{d}(t) n\right)+n\left(s^{L}+t\right)} .
$$

Differentiation with respect to $t$ yields an overly cumbersome expression whose denominator

\footnotetext{
${ }^{25}$ Existence follows Lemma 2. Alternatively, it can also be shown that for $t$ and $c$ sufficiently small, there is an interior solution at $\hat{k}$.
} 
is squared, and its numerator's sign turns on

$$
-k\left[(1-z) \bar{s}+z s^{L}\right]-z s^{L}(n+2)-c n(1-z)<0
$$

\section{B.4 Proof of Proposition 3}

Proposition 3 As the number of firm-country pairs becomes large, there is always shipping the good apples: $\left.\frac{d\left(Q_{x}^{H} / Q_{x}^{L}\right)}{d t}\right|_{n \rightarrow \infty} \geq 0$.

Proof. Total high quality exported to the export country is

$$
n x_{d}^{H}(n)(1-z) q_{d}(n)=\frac{n 2(1-z)}{\kappa(n)} \frac{n+3}{2(n+1)} \frac{\bar{s}-\frac{\kappa(n)}{(n+3) k} c-\frac{2 t}{(n+3) k}}{\left[(1-z) \bar{s}+z s^{L}\right]}-(1-k) \frac{n}{\kappa(n)}
$$

The limit as $n$ becomes large the right-hand-side becomes

$$
\lim _{n \rightarrow \infty} n x_{d}^{H}(n)(1-z) q_{d}(n)=\frac{k\left((1-z) \bar{s}+z s^{L}\right)-(1-k) z s^{L}-(1-z) c}{k\left((1-z) \bar{s}+z s^{L}\right.} .
$$

Clearly the numerator changes sign for small enough $k$. Solving for $k$ such that the expression is zero obtains $\hat{k}$. That is, in the limit, for any $k$ below $\hat{k}$, total high quality in the export market is zero. Therefore, any increase in $t$ has no effect on total high quality in the export market: for $k<\hat{k},\left.\frac{d\left(Q_{x}^{H} / Q_{x}^{L}\right)}{d t}\right|_{n \rightarrow \infty}=0$, if it is defined (in the limit there is positive amounts of low-quality output if $k>0$, and in particular at $\hat{k}$. Specifically, the critical $k$ for total low-quality output is zero in the limit. Alternatively, total low quality in the export market in the limit does not depend on $k$. (It does of course depend on $t$, etc.)). 


\section{B.5 Proof of Proposition 4}

Proposition 4 When only the export market low-quality demand is scaled by $k$ relative to the domestic markets, if

$$
k>\tilde{k} \equiv \frac{\bar{s}^{2}-(1-z)\left(s^{H}-s^{L}\right)\left(z s^{L}+c\right)}{s^{L}\left[(1-z) \bar{s}+z s^{L}\right]}, \tilde{k} \in\left(1, \frac{s^{H}}{s^{L}}\right)
$$

then $d\left(Q_{x}^{H} / Q_{x}^{L}\right) / d t<0$ : if the willingness-to-pay in the export market for low quality is sufficiently large, then an increase in the per-unit transport cost decreases the relative quantity demanded for high quality in the export market.

Proof.

$$
\begin{aligned}
\frac{Q_{x}^{H}}{Q_{x}^{L}} & =\frac{(1-z) x_{d}^{H} q_{d}}{z x_{d}^{L} q_{d}} \\
& =\frac{s^{L} \kappa(2)\left[2(1-z)\left(s^{H}-s^{L}\right) q_{d}(t)+s^{L}(1-k)\right]}{2 s^{L}\left[\kappa(2) z\left(s^{H}-s^{L}\right)+3(1-k)\left(s^{H}\right)\right] q_{d}(t)-t\left(5 s^{H}-\kappa(2) s^{L}\right)-5(1-k) s^{H} s^{L}}
\end{aligned}
$$

Denoting the denominator $\Delta$ and differentiating with respect to $t$ yields

$$
\begin{aligned}
\frac{d\left(Q_{x}^{H} / Q_{x}^{L}\right)}{d t}= & \frac{s^{L} \kappa(2)\left(5 s^{H}-\kappa(2) s^{L}\right)}{\Delta^{2}} \\
& \times\left\{-2\left[s^{L} \bar{s}(1-k)+(1-z)\left(s^{H}-s^{L}\right) t\right] \frac{d q_{d}}{d t}+2(1-z)\left(s^{H}-s^{L}\right) q_{d}(t)+s^{L}(1-k)\right\}
\end{aligned}
$$

where from 22 ,

$$
\frac{d q_{d}}{d t}=\frac{1}{6} \frac{-\left(5 s^{H}+\kappa(2) s^{L}\right)}{\left[(1-z) \bar{s}+z s^{L}\right] \kappa(2)\left(s^{H}-k s^{L}\right)-2(1-k) s^{H} s^{L}} .
$$

Substituting (22) for $q(t)$ and (B.3) for $d q_{d} / d t$ in (B.2), and solving for $k$ yields three roots, only one in $\left[0, \frac{s^{H}}{s^{L}}\right]$ :

$$
\tilde{k}=\frac{\bar{s}^{2}-(1-z)\left(s^{H}-s^{L}\right)\left(z s^{L}+c\right)}{s^{L}\left[(1-z) \bar{s}+z s^{L}\right]} .
$$


To show that $\tilde{k}>1$, the expression is decreasing in $c$, and the $c$ such that $\tilde{k}=1$ equals $\bar{s}$, which violates the assumption that some low-quality production is efficient $\left(c<s^{L}\right)$ or the weaker assumption that some expected production is efficient. To show that $\tilde{k}<s^{H} / s^{L}$, the $c$ such that $\tilde{k}=s^{H} / s^{L}$ equals $-z s^{L} /(1-z)$ which violates the assumption that $c \geq 0$.

\section{B.6 Proof of Lemma 6}

Lemma 6 When the export market is scaled by $k$ relative to the domestic markets and $t=0$, $d x_{d}^{H} / d v<0$, as the ad valorem tariff/transport cost increases, the fraction of high-quality good exported decreases when the per-unit transport cost is zero.

Proof. Differentiating high-quality export share $x_{d}^{H}(15)$ with respect to ad valorem tariff $v$

$$
\frac{d x_{d}^{H}}{d v}=k \frac{6 q(v)(1-z)-5}{[3 k+2(v+1)]^{2}(1-z) q(v)}-\frac{k-v-1}{[3 k+2(v+1)]^{2}(1-z) q^{2}(v)} \frac{d q(v)}{d v} .
$$

The maximum home and export outputs (i.e., when all costs are zero) are $1 / 2$ and 1/3, so the maximum output $q$ is $5 / 6$, so the first term is negative. Since from $28 d q(v) / d v<0$, if $k<1+v, d x_{d}^{H} / d v<0$. Likewise, as $k \rightarrow \infty, d x_{d}^{H} / d v<0$. Setting, $t=0$ and using 28 yields

$\frac{d x_{d}^{H}}{d v}=\frac{6 k}{\Delta}\left[-c(3 k+2(v+1))^{2}(1-z)(\bar{s}-c)-25 k^{2} z S^{L} \bar{s}+d(3 k+2(v+1))\left[(7 k-2(v+1)) S^{L} c\right]\right.$

where $\Delta=(1-z)(3 k+2(v+1))[5 k \bar{s}-c(3 k+2(v+1))]^{2}>0$. The first bracketed term is negative, the question is the sign of the remaining two. The only roots for $k$ are imaginary, and for arbitrary values the last two terms are negative.

\section{B.7 Proof of Proposition 5}

Proposition 5 When only the export market low-quality demand is scaled by $k$ relative to the domestic markets, $d\left(P_{x}^{H} / P_{x}^{L}\right) / d t<0$ : an increase in a per-unit transport cost always decreases the price of the high-quality good relative to the low-quality good. 
As an outline here is the proof for the benchmark

\section{Proof.}

$$
\frac{P_{x}^{H}}{P_{x}^{L}}=\frac{s^{H}\left(1-Q_{x}^{H}\right)-k s^{L} Q_{x}^{L}}{k s^{L}\left[1-\left(Q_{x}^{H}+Q_{x}^{L}\right)\right]} .
$$

Because of the asymmetry of markets, the expression does not simplify as neatly as for Proposition 2

$\frac{P_{x}^{H}}{P_{x}^{L}}=\frac{\left(5 s^{H}-\kappa(2) s^{L}\right) 2 t k-4 q_{d}(t)\left[\left(s^{H}-s^{L}\right) \kappa(2) \bar{s}_{x}-3 s^{L} s^{H}(1-k)\right]+s^{H}\left[5 \kappa(2) s^{H}-\left(13 k^{2}+4 k+8\right) s^{L}\right]}{k\left[5 s^{H}-\kappa(2) s^{L}\right]\left[s^{L}\left(k+4-4 q_{d}(t)\right)+2 t\right]}$,

where $\bar{s}_{x} \equiv(1-z) s^{H}+z k s^{L}$ and recall that $\kappa(2)=2+3 k$. Letting $\Delta \equiv k\left[5 s^{H}-\kappa(2) s^{L}\right]\left[s^{L}(k+\right.$ $\left.\left.4-4 q_{d}(t)\right)+2 t\right]$, differentiating $P^{H} / P^{L}$ with respect to $t$ yields

$$
\begin{aligned}
\frac{2 k \kappa(2)^{2}\left(s^{H}-k s^{L}\right)}{\Delta^{2}} & \left\{4(1-z)\left(s^{H}-s^{L}\right) q(t)-\left(5 s^{H}-(4+k) s^{L}\right)\right. \\
- & {\left[4(1-z)\left(s^{H}-s^{L}\right) t+2 s^{L}\left[\left((1-z) s^{H}+z s^{L}\right) k-\left(4 z\left(s^{H}-s^{L}\right)+s^{H}\right)\right] \frac{d q(t)}{d t}\right\} . }
\end{aligned}
$$

Substituting (22) for $q(t)$ and (B.3) for $d q_{d} / d t$ in (B.4), obtains

$$
(-\kappa(2) / 3)\left(5 s^{H}-\kappa(2) s^{L}\right) \frac{\left.\left(s^{H}-s^{L}\right)\left[(1-z) \bar{s}_{x}+z k s^{L}+2 c(1-z)\right]-s^{L}\left[4 s^{L} z+s^{H}(k-1-4 z) d\right)\right]}{\kappa(2)\left(s^{H}-s^{L}\right)\left[(1-z) \bar{s}_{x}+z k s^{L}\right]+3 k s^{H} s^{L}(1-k)} .
$$

For the denominator of (B.5), collecting on $k$, the non- $k$ coefficient term is positive. The remainder is positive, so long as $k$ is less than a critical $k$, denoted $k^{\prime}$. It is straightforward to show that $k^{\prime}<s^{H} / s^{L}$. Thus, the denominator is positive. Similarly, the numerator is positive, so long as $k$ is less than a different critical $k$, denoted $k^{\prime \prime}$ and it is straightforward to show too that $k^{\prime \prime}<s^{H} / s^{L}$. Thus, the derivative is always negative.

\section{B.8 Proof of Proposition 8}

Proposition 8 In a duopoly, when the export market is scaled by $k$ relative to the domestic markets, if $t=0$, or $t \rightarrow 0, c \rightarrow 0$, then $d\left(Q_{x}^{H} / Q_{x}^{L}\right) / d v<0$ : if the per-unit transport cost is 
not too large, then an increase in the ad valorem decreases the relative quantity demanded for high quality in the export market.

Proof.

$$
\frac{Q_{x}^{H}}{Q_{x}^{L}}=\frac{(1-z) x_{d}^{H} q_{d}}{z x_{d}^{L} q_{d}}=\frac{s^{L}\left[2(v+1)(1-z) q_{d}(t)+k-1-v\right.}{(v+1)\left(2 s^{L} z q_{d}(v)-t\right)}
$$

Differentiating with respect to $v$ yields

$\frac{d\left(Q_{x}^{H} / Q_{x}^{L}\right)}{d v}=-s^{L}\left(\frac{2(1+v)\left[\left(z(k-v-1) s^{L}+t(1+v)(1-z)\right]\right.}{\left(2 s^{L} z q_{d}-t\right)^{2}(1+v)^{2}} \frac{d q_{d}}{d v}+\frac{k\left(2 s^{L} z q_{d}-t\right)}{\left(2 s^{L} z q_{d}-t\right)^{2}(1+v)^{2}}\right)$,

where from 28 ,

$$
\frac{d q_{d}}{d v}=\frac{-(c+t)}{3 k\left[(1-z) \bar{s}+z s^{L}\right]}<0 .
$$

As the second parenthetical term in B.6 is positive, then $t$ and $c$ arbitrarily small results in a negative expression for $d\left(Q_{x}^{H} / Q_{x}^{L}\right) / d v$.

If $t=0$, then B. 6 becomes

$$
-3 k(1-z)\left(\bar{s}+z s^{L}\right) \frac{5 k^{2} \bar{s}-c\left[s k^{2}+4(v+1)+2(v+1)^{2}\right]}{(1+v)^{2} z[5 k \bar{s}-c(3 k+2(1+v))]^{2}} .
$$

There are no real roots in $k$ for the above expression (one imaginary) as by the efficiency assumption $\bar{s}>c$, and for arbitrary values the expression is negative. 


\section{References}

Alchian, A. and Allen, W., 1964, University Economics. Belmont, CA: Wadsworth Publishing Company.

American Merchandise Liquidators, 2012, http://www.amlinc.com/2012/06/how-to-exportliquidation-merchandise/.

Beijing Review, 2015. What's behind the lowly status of 'Sold in China?' No. 12., 19 March.

Boom, A. 1995, Asymmetric International Minimum Quality Standards and Vertical Differentiation. The Journal of Industrial Economics, 43(1), 101-119. doi:10.2307/2950427

Borcherding, T.E. and E. Silberberg, 1978, Shipping the Good Apples Out: The Alchian and Allen Theorem Reconsidered, Journal of Political Economy 86:1, 131-138

Brander, J. and Krugman, P., 1983. A 'reciprocal dumping' model of international trade. Journal of international economics, 15(3-4), pp.313-321.

Brander, J.A. and Spencer, B.J., 1985. Export subsidies and international market share rivalry. Journal of international Economics, 18(1-2), pp.83-100.

Chisholm, D. C. and G. Norman, 2012, Market Access and Competition in Product Lines, International Journal of Industrial Organization, 30, 5 Pages: 429-435

Costinot, A., 2009, On the origins of comparative advantage, Journal of International Economics, 77, pp. 255-264.

Cremer, H., and J.-F. Thisse, 1991, Location Models of Horizontal Differentiation: A Special Case of Vertical Differentiation Models, Journal of Industrial Organization, 39(4), 383-390.

Crampes, C., and A. Hollander, 1995, Duopoly and quality standards, European Economic Review, Volume 39, Issue 1, January, Pages 71-82. 
Creane, A., and T.J. Jeitschko, 2016 Exporting to Bypass Weak Institutions: Shipping the good apples out under asymmetric information, European Economic Review, April, Vol. 85(2), pp. 246-262.

De Fraja, G., 1996, Product Line Competition in Vertically Differentiated Markets. International Journal of Industrial Organization, Vol. 14, pp. 389-414

Carsten E., J. P. Neary; 2010. Multi-Product Firms and Flexible Manufacturing in the Global Economy, 2010, Review of Economic Studies; 77 (1): 188-217.

Gal-Or, E., 1983, Quality and Quantity Competition, Bell Journal of Economics, 14, pp. 590-600.

Global Sources, 2016, What do suppliers do with rejected products? htttps://www.globalsources.com/NEWS/SIC-what-do-suppliers-do-with-rejectedproducts.HTM

Gould, J. P., and Segall, J., 1968, The Substitution Effects of Transportation Costs, Journal of Political Economy, 77(1), 130-37.

Handshake, 2015, Off-price Retailers: What Wholesalers Need to Know, https://www.handshake.com/blog/off-price-retailers

Hummels, D. and Skiba, A., 2004, Shipping the Good Apples Out? An Empirical Confirmation of the Alchian-Allen Conjecture. Journal of Political Economy, 112(6), 1384-1402.

Johnson, J.P. and D.P. Myatt, Multiproduct Cournot Oligopoly, The RAND Journal of Economics, Vol. 37, No. 3 (Autumn, 2006), pp. 583-601.

Johnson, J.P.; Myatt, D.P., 2015, The properties of product line prices, International Journal of Industrial Organization, 43, 182-188

Market Wired, 2012, http://www.marketwired.com/press-release/inventory-distortion-an800b-issue-for-retailers-worldwide-1655373.htm 
Mussa, M. and Rosen, S., 1978, Monopoly and product quality, Journal of Economic Theory, Volume 18, Issue 2, Pages 301-317.

Norton, M. I., and J. Dann, 2013, "Juan Valdez: Innovation in Caffeination." Harvard Business School Case 513-090, February.

Park, JH, 2001, The Canadian Journal of Economics, 34 Issue: 4 Pages: 967-987, 2001.

Rey, P. and J. Tirole, 1986, The Logic of Vertical Restraints, The American Economic Review, 76(5), 921-939.

Rico, R.J., 2015, What happens to the losing team's Super Bowl championship shirts? The Guardian, Tuesday 3 February 06.00 EST.

Ries, J., 1993, Voluntary Export Restraints, Profits, and Quality Adjustment. The Canadian Journal of Economics, 26(3), 688-706.

Ronnen, U., 1991, Minimum quality standard, fixed costs, and competition, Rand Journal of Economics 22, no. 4, 490-504

Tirole, J., 1988, Theory of Industrial Organization, MIT Press.

Wikipedia, 2019, Second Wine, https://en.wikipedia.org/wiki/Second_wine.

Wikinvest, 2017, Off-Price Retail, http://www.wikinvest.com/industry/Off-priceRetail

Zhou, DS; Spencer, BJ; Vertinsky, I, 2002, Journal of International Economics, 56 Issue: 1 Pages: 205-232 